

\section{Sumário}

Dossiê TEMÁTICO: NOVOS INSTITUTOS JURÍDICOS DE LICITAÇÕES E CONTRATOS 17

I. LicitaÇõEs E CONTRATOS PÚBLICOS: PARTE GERAL. 18

INTEGRATED CONTRACT IN LAW 14.133/2021: NEW LAW, SAME PROBLEMS? A STUDY OF COMPARATIVE LAW .20

Paulo Afonso Cavichioli Carmona, Bruno Ribeiro Marques e Odilon Cavallari

Reajustamento de preços na Nova Lei de Licitações e Contratos Administrativos BRASILEIRA: O "Princípio" Da ANUALIDAde.

Ricardo Silveira Ribeiro e Bráulio Gomes Mendes Diniz

A nova Lei de Licitações, as encomendas tecnológicas e o diálogo competitivo .61 André Dias Fernandes e Débora de Oliveira Coutinho

LiCITAÇÕES, CONTRATOS E O IMPULSO À APRENDIZAGEM PROFISSIONAL: UM ESTUDO SOBRE A CONTRATAÇÃo de APRENDizes no ESTAdo do AMAZONAS, BRAsIL

Emerson Victor Hugo Costa de Sá, Natasha Yasmine Castelo Branco Donadon e Mauro Augusto Ponce de Leão Braga

Licitações, contratos e Modelo Brasileiro de Processo: notas sobre a viabilidade DA UTILIZAÇÃo DE FERRAMENTAS PROCESSUAIS PARA CONFERIR MAIOR EFICIÊNCIA ÀS AQUISIÇÕES PÚBLICAS

Claudio Madureira e Carlos André Luís Araujo

RESOlUÇão DE CONFLITOS COM A ADMINISTRAÇÃo PÚBLICA E A NOVA LEI DE LICITAÇÕES E CONTRATOS: REFORÇO DOS MEIOS ALTERNATIVOS.

Clarissa Sampaio Silva e Danille Maia Cruz

A Adesão do Brasil ao Acordo sobre Contratações Públicas da OMC: entre tabus e DIFICULDADES REAIS

Eduardo Ferreira Jordã e Luiz Filippe Esteves Cunha

II. Accountability e controle

A LEI N. ${ }^{\circ}$ 14.133/2021 E OS NOVOS LIMITES do CONTROLE EXTERNO: A NECESSÁRIA DEFERÊNCIA dos Tribunais de Contas em prol da Administração Pública .................................. 162 Ricardo Schneider Rodrigues

O CONTROLE DAS CONTRATAÇÕES PÚBliCAS E A NOVA LEI DE LICITAÇÕES: O QUE HÁ DE Novo? 183

Leandro Sarai, Flávio Garcia Cabral e Cristiane Rodrigues Iwakura 
Programa de compliance como exigênCia em licitações: ANálises EM Prol da QUALIFICAÇÃo DO PROCESSO LICITATÓRIO NO CONTEXTO DA LEI 14.133/2021.

Cristian Ricardo Wittmann e Anayara Fantinel Pedroso

A NOVA REALIDAde bRASILEIRA DE NECESSIDADE DE PROGRAMAS DE INTEGRIDADE DAS PESSOAS JURÍDICAS LICITANTES EM PROCESSOS LICITATÓRIOS DA ADMINISTRAÇÃO PÚBLICA 227

Fernando Silva Moreira dos Santos e Luiz Fernando de Oriani e Paulillo

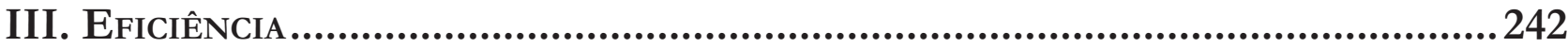

Efficiency contracts in the New Brazilian Procurement Law: conceptual FRAMEWORK AND INTERNATIONAL EXPERIENCE

Floriano de Azevedo Marques Neto, Hendrick Pinheiro e Tamara Cukiert

A gestão de riscos como instrumento para a aplicação efetiva do Princípio Constitucional dA EFICIÊNCIA.

Rafael Rabelo Nunes, Marcela Teixeira Batista Sidrim Perini e Inácio Emiliano Melo Mourão Pinto

IV. Contratação PÚblica No Direito ESTrangeiro

LA ADQUisición de VACUNAS CONTRA LA COVID-19 POR COLOMBIA: ENTRE LA CONFIDENCIALIDAD Y LA FALTA DE TRANSPARENCIA. 284

Gressy Kareny Rojas Cardona e David Mendieta

LA DISCRIMINACIÓN EX POST DE LOS OFERENTES DE UNA LICITACIÓN PÚBLICA COMO INFRACCIÓN ADMINISTRATIVA Y DE LIBRE COMPETÊNCIA 312 Jaime Arancibia Mattar

LA DISCRIMINACIÓN EX POST DE LOS OFERENTES DE UNA LICITACIÓN PÚBLICA COMO INFRACCIÓN ADMINISTRATIVA Y DE LIBRE COMPETÊNCIA..........................................................332 Udochukwu Uneke Alo, Obiamaka Adaeze Nwobu e Alex Adegboye

Outros Temas 348

I. Políticas públicas e institucionalidade

¿Existe El derecho humano a la identidad Cultural de los Migrantes en El Derecho INTERNACIONAL? 351 Juan Jorge Faundes e Glorimar Alejandra Leon Silva

El acceso a la justicia y el debido proceso ante el Tribunal Constitucional y la CorTe Suprema: dos NOCIONES DEL CONTENCIOSO ADMINISTRATIVO CHILENO .384 Pedro Harris Moya 
“Ministrocracia” E DECISÕES INDIVIDUAis CONTRAditórias No Supremo Tribunal FEDERAI

Ulisses Levy Silvério dos Reis e Emilio Peluso Neder Meyer

A POlÍtica de INOVAÇÃo COMO INSTRUMENTO DE REDUÇÃo DAS DESIGUALDADES REGIONAIS NO BRASIL

Caroline Viriato Memória e Uinie Caminha

Conflitos de Competência E A JudicializaÇão da Saúde no Federalismo Brasileiro.447 Jorge Leal Hanai, Luis Antônio Abrantes e Luiz Ismael Pereira

O Ministério Público no enfrentamento dos Reflexos da CRise da Covid-19: UMA

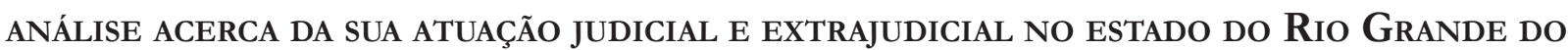
NorTE

Raquel Maria da Costa Silveira, Ana Mônica Medeiros Ferreira, Flávio Luiz Carneiro Cavalcanti e Haroldo Helinski Holanda

A CONSAgRaÇão CONSTITUCIONAL DA POlítica FALIMENTAR

Nuno de Oliveira Fernandes

II. Políticas públicas, grupos vulneráveis e litígios estruturais

LAS LIMITACIONES A LOS DERECHOS DE LOS GRUPOS VULNERABLES Y LOS SUJETOS DE ESPECIAL PROTECCIÓN DURANTE LA PANDEMIA Mary Luz Tobón Tobón

LitígIOS ESTRUTURAIS E A PROTEÇÃO DOS DIREITOS DOS POVOS INDÍGENAS DURANTE A PANDEMIA DE Covid-19: CONTRIBUições do ICCAL

Ana Carolina Lopes Olsen e Bianca M. Schneider van der Broocke

EPISTEMICÍDIO DAS NARRATIVAS NEGRAS E LITÍGIO ESTRUTURAL: INSTRUMENTOS EXTRAJUDICIAIS PARA DISSOLUÇÃO DO PROBLEMA NO SISTEMA EDUCACIONAL .......................................582

Vitor Fonsêca e Caroline da Silva Soares

Trajetórias E DiRETRIZES dAS POlíticas PÚbliCAS NACIONAIS PARA A POPULAÇão INFANTOJUVENIL EM SITUAÇÃO DE RUA...

Wânia Cláudia Gomes Di Lorenzo Lima, Cynthia Xavier de Carvalho e Maria Creusa de A. Borges

Emprendimiento como Fuente de Ingresos para las Víctimas del Conflicto Armado en el Marco de la Ley 1448 de Colombia. Reflexiones de la Implementación en el Valle del Cauca

Saulo Bravo García e Luz Marina Restrepo García

III. Políticas públicas e aÇão Restaurativa. 
JUSTIÇA RESTAURATIVA COMO AÇÃO COMUNICATIVA: EQUILÍBRIO ENTRE SISTEMA E MUNDO DA

Daniela Carvalho Almeida da Costa e Luciana Leonardo Ribeiro Silva de Araújo

JUSTIÇA RESTAURATIVA: ACORDOS E COOPERAÇÃO.................................................668

Samyle Regina Matos Oliveira e Selma Pereira de Santana 


\title{
La adquisición de vacunas contra la COVID-19 por Colombia: entre la confidencialidad y la falta de transparencia*
}

\author{
The acquisition of vaccines against COVID-19 \\ by Colombia: between confidentiality and lack \\ of transparency
}

\section{A aquisição de vacinas contra COVID-19 pela Colômbia: entre a confidencialidade e a falta de transparencia}

Gressy Kareny Rojas Cardona**

David Mendieta***

\section{Resumen}

A través de un método de interpretación basado en la revisión documental, el artículo realiza una crítica a la imposibilidad de realizar la vigilancia oportuna al proceso de negociación del Gobierno colombiano con las farmacéuticas para adquirir las vacunas de la COVID-19, con lo que se le dio prevalencia a la confidencialidad como prerrogativa de libre mercado sobre el principio de transparencia como potestad estatal mediante la aplicación de una vigilancia oportuna y adecuada. Primero, se realiza un análisis de los decretos que le conceden facultades extraordinarias al presidente de la República y las disposiciones jurisprudenciales de las altas cortes. Luego, se plantea el fundamento normativo del principio de transparencia como principio rector de la contratación estatal. Se plantea además un contraste entre la posibilidad de imponer cláusulas de confidencialidad, propia de la contratación privada, con la exigencia del ejercicio de la vigilancia como garantía de transparencia en negociaciones que involucran las finanzas públicas. Finalmente, al evidenciar la tensión entre el libre mercado y derechos fundamentales, se realiza una reflexión respecto al déficit de salvaguarda del derecho a la salud debido a la falta de vigilancia oportuna que, debido a que el principio de transparencia se subordina a la confidencialidad, deja abierta la posibilidad de crisis de legitimidad, credibilidad y confianza en el Estado.

Palabras clave: Empresas farmacéuticas; Vigilancia y control; Libre mercado; Derecho a la salud; Oferta y demanda

*** Doctor en Derecho Constitucional. Direc $\neg$ tor del Doctorado en Derecho de la Universi-dad de Medellín, miembro del Grupo de Inves $\neg$ tigaciones Jurídicas de la Facultad de Derecho de la Universidad de Medellín. MedellínCo $\neg$ lombia. https://orcid.org/0000-0002-69446815

E-mail:dmendieta@udemedellin.edu.co

** Abogada, Máster en Derecho, Candidata a Doctor, Universidad de Medellín. https://orcid. org/0000-0003-3860-6772

E-mail: rojascardona.gressykareny@gmail.com 


\section{Abstract}

Through an interpretation method based on the documentary review, the article criticizes the impossibility of carrying out timely surveillance of the negotiation process of the Colombian Government with pharmaceutical companies to acquire COVID-19 vaccines, thereby It gave priority to confidentiality as a free market prerogative over the principle of transparency as a state authority through the application of timely and adequate surveillance. First, an analysis is made of the decrees that grant extraordinary powers to the President of the Republic and the jurisprudential provisions of the high courts. Then, the normative foundation of the principle of transparency is proposed as the guiding principle of state contracting. There is also a contrast between the possibility of imposing confidentiality clauses, typical of private contracting, with the requirement to exercise vigilance as a guarantee of transparency in negotiations involving public finances. Finally, by highlighting the tension between the free market and fundamental rights, a reflection is made regarding the deficit in safeguarding the right to health due to the lack of timely surveillance that, because the principle of transparency is subordinated to confidentiality, it leaves open the possibility of a crisis of legitimacy, credibility and trust in the State.

Keywords: Pharmaceutical companies; Surveillance and control; Free market; Right to health; Supply and demand

\section{Resumo}

Por meio de um método de interpretação baseado na revisão documental, o artigo critica a impossibilidade de fiscalizar atempadamente o processo de negociação do Governo colombiano com as empresas farmacêuticas para a aquisição das vacinas COVID-19, dando prioridade ao sigilo como prerrogativa do mercado livre sobre o princípio da transparência como autoridade estatal por meio da aplicação de vigilância oportuna e adequada. Primeiramente, são analisados os decretos que outorgam poderes extraordinários ao Presidente da República e as disposições jurisprudenciais dos tribunais superiores. Em seguida, o fundamento normativo do princípio da transparência é proposto como o princípio norteador da contratação estadual. Há também o contraste entre a possibilidade de impor cláusulas de sigilo, típicas da contratação privada, com a exigência do exercício da vigilância como garantia de transparência nas negociações envolvendo finanças públicas. Por fim, ao evidenciar a tensão entre o mercado livre e os direitos fundamentais, reflete-se sobre o déficit na salvaguarda do direito à saúde pela falta de vigilância atempada que, por estar subordinado o princípio da transparência ao sigilo, deixa em aberto o possibilidade de crise de legitimidade, credibilidade e confiança do Estado.

Palavras-chave: Companhias farmaceuticas; Vigilância e controle; Mercado livre; Direito à saúde; Oferta e demanda

\section{Introducción}

El presente artículo se ocupa del problema de la aplicación del principio de transparencia en el proceso de negociación realizado por el Gobierno colombiano para adquirir las vacunas de la COVID-19 a la luz de las potestades permitidas por la emergencia social, económica y ecológica declarada por el Presidente con la firma de todos sus ministros y teniendo en cuenta la tensión entre la confidencialidad del libre mercado y la necesidad de ejercer la vigilancia y la preservación de la transparencia en una dinámica en la que el derecho a la salud se encuentra en riesgo y en la que, además, hay dineros públicos invertidos. 
La tesis de la presente investigación es que no es aceptable en el Estado Constitucional y Democrático de Derecho sacrificar el principio de la transparencia en las actividades contractuales del Estado en aras del acatamiento de cláusulas de confidencialidad, así nos encontremos en un momento de extrema excepcionalidad como lo es una pandemia. Durante los casi dos años de duración de la crisis global ocasionada por el virus de la COVID-19, muchos son los derechos y libertades limitados y suspendidos por los estados con el argumento de la salvaguarda de la salubridad pública, pero ¿puede renunciarse a un principio rector de la contratación estatal como lo es la transparencia con el propósito de defender la libertad de mercado y la propiedad intelectual en cabeza de las farmacéuticas? ¿puede ser compatible una contratación transparente con una calamidad global? Responder los anteriores interrogantes para el caso colombiano justifican la realización de la presente investigación.

En Colombia, diferentes Organizaciones No Gubernamentales y personas naturales han intentado acceder a través de derechos de petición a los contratos celebrados por el Estado colombiano y las multinacionales farmacéuticas con el fin de adquirir por el parte del primero, las vacunas contra el virus de la COVID 19, pero el Gobierno Nacional les ha negado dicho acceso alegando que se trata de información reservada por la existencia de cláusulas de confidencialidad en dichos contratos. Hubo quienes hicieron uso del recurso de insistencia ante el Tribunal Superior de Cundinamarca, como lo fueron el Instituto Internacional de Estudios Anticorrupción y el abogado Ramiro Bejarano y en decisiones del alto tribunal con fechas 11 y 13 de mayo, le ordenó a la Unidad Nacional para la Gestión del Riesgo de Desastres (UNGRD) la entrega de los contratos en los siguientes términos: "Se observa que la confidencialidad de los mismos se restringe a las disposiciones de carácter financiero o sobre indemnización descritos en éste y puntualmente respecto del precio por dosis del producto, circunstancia que carece de sustento alguno, máxime cuando los artículos 9 y 10 de la Ley 1712 de 2014 por medio de la cual se creó la Ley de Transparencia y del Derecho de Acceso a la Información Pública Nacional disponen el deber de publicidad considerando que se trata del empleo de recursos públicos y destinados a realizar los fines del Estado" y enfatiza en la conveniencia de hacer púbica esta información y que otros estados ya lo han hecho: "La liberación de la información sobre la adquisición de las vacunas no ha tenido consecuencias negativas, y al contrario, permiten unas mejores prácticas, controles y opiniones fundamentadas, de manera que aumenta la confianza y la transparencia, incluso para lograr que las personas venzan las resistencias a vacunarse resulta importante el conocimiento de la información."

El Gobierno Nacional hizo solicitudes de adición y aclaración de las sentencias proferidas e incluso existen contra estas, varios incidentes de nulidad, propuestos por el Gobierno y las farmacéuticas. La multinacional Janssen Cilag S.A, presentó dos tutelas contra las dos sentencias del Tribunal Superior de Cundinamarca ante el Consejo de Estado las cuales fueron negadas en el mes de agosto; precisamente por estar pendiente que este Tribunal se pronuncie frente a la gran cantidad de recursos y peticiones que tiene pendientes sobre el caso, así: "En ese orden de ideas, las pretensiones de la presente acción resultan a todas luces improcedentes, ya que la autoridad judicial competente para decidir acerca de la presunta nulidad por falta de vinculación de las sociedades Janssen Cilag S.A. y otras, al proceso de insistencia iniciado por el Instituto Internacional de Estudios Anticorrupción, es el Tribunal accionado, quien se encuentra pendiente de decidir acerca de diferentes solicitudes elevadas por las partes".

Pasan los meses y el Gobierno insiste en no hacer públicos los contratos de adquisición de las vacunas contra la COVID-19 a pesar de existir decisiones judiciales que se lo ordenan y ha preferido dilatar su obligación con el uso de artilugios judiciales. Lo anterior deja en entredicho el papel jugado por el ejecutivo colombiano para enfrentar la pandemia, pues en el Estado Constitucional y Democrático de Derecho no pueden existir actos de los poderes públicos carentes de control. El secretismo asumido por el Gobierno Nacional pone un manto de duda en las finanzas públicas.

La estructura del artículo tiene cinco partes. La primera plantea el contexto a partir del cual se discute la indisponibilidad de los documentos de la negociación entre el Gobierno colombiano y las farmacéuticas para la adquisición de las dosis de las vacunas. La segunda, se ocupa de la normativa y jurisprudencia co- 
lombiana respecto a la emergencia; la tercera, del fundamento normativo del principio de transparencia. La cuarta, de la relación entre confidencialidad en la contratación privada y vigilancia en la contratación pública; y la quinta, de la tensión entre libre mercado y derechos fundamentales al tener en cuenta la legítima aspiración de las farmacéuticas por lucrarse y la salvaguarda del derecho a la salud de los ciudadanos.

Se concluirá que el secretismo en la negociación y adquisición de las vacunas ha configurado una crisis de legitimidad, credibilidad y confianza en el Estado; en términos que son estrictamente negociales y financieros, las multinacionales, en este caso, las farmacéuticas, tratan al Estado como a un cliente; la posición dominante de tales empresas hace que se olvide un aspecto determinante: todo privado que contrata con el Estado es prestador de un servicio y está sujeto a vigilancia y control, no es cosa de mera lex mercatoria; y por tanto, hay una inconsistencia normativa en la invocación de la confidencialidad que se desentiende de la aplicación del principio de transparencia. ${ }^{1}$

\section{Contexto de la problemática: reseña en medios de indisponibilidad de documentos del proceso de negociación de la adquisición de las vacunas para la COVID-19}

La situación de una emergencia sanitaria como la producida por la pandemia de la COVID-19 no implica la eliminación de los mecanismos de vigilancia, los cuales necesitan del derecho al acceso a la información de procesos delicados, incluyendo los de adquisidores de vacunas a multinacionales farmacéuticas. En tiempos de pandemia, la actuación pública exige la conservación e implementación de mecanismos y procedimientos que garanticen el buen gobierno, transparente y eficiente, con el fin de prevenir el fraude y la corrupción que son tan perjudiciales para el interés público y la sociedad en general².

El de la negociación entre los estados y las farmacéuticas que, al ser las que proveen las vacunas contra la COVID-19, han asumido una posición dominante al imponerles a los primeros, cláusulas de confidencialidad. Además, la posterior ineficiencia en el proceso de distribución de las vacunas adquiridas, situación que las negociaciones confidenciales iban a evitar, justifica de facto esta inquietud jurídica respecto a la ausencia de la documentación requerida para garantizar que los mecanismos de vigilancia impidan que los riesgos de una negociación desventajosa o de una gestión ineficiente terminen afectando tanto la garantía de derechos fundamentales como la salud y la vida, como el manejo eficiente y adecuado de los dineros públicos. ${ }^{3}$

El Gobierno de Colombia, considera que la confidencialidad de los acuerdos para adquirir vacunas resultaba indispensable para participar de un mercado altamente competitivo y obtener las dosis necesarias ${ }^{4}$. Se trata, en suma, de desatención del principio de transparencia que, además de dejar de ser el principio medular de la contratación pública ${ }^{5}$ y en la lucha contra la corrupción ${ }^{6}$, elimina toda opción de reivindicar la confianza, la credibilidad y la legitimidad del Estado. El principio de transparencia establece el diálogo entre

\footnotetext{
1 PIZARRO WILSON, Carlos. Un vistazo general a los Principios Latinoamericanos de Derecho de los Contratos. Revista de Derecho Privado, n. 35, p. 351-368, Jul./Dic. 2018. DOI: 10.18601/01234366.n35.13

2 LIMA, Luciana Cristina da Conceição; GONÇALVES, Alcindo Fernandes; REI, Fernando Cardoso Fernandes; LIMA, Cláudio Benevenuto de Campos. Compliance em tempos de calamidade pública: análise sobre a flexibilização da transparência de dados e informações durante o enfrentamento da COVID-19 no Brasil. Revista Brasileira de Políticas Públicas, Brasília, v. 11, n. 1. p. 168-187, 2021.

3 GARCÍA OTERO, Ruth; HERNÁNDEZ PALMA, Oona Isabel. Derechos humanos y mecanismos de control normativo internacional en el marco de la pandemia. Covid-19: reflexión desde el control de convencionalidad. Utopía y Praxis Latinoamericana, v. 25, n. Esp.8, 2020. DOI: https://doi.org/10.5281/zenodo.4082011.

4 GATTI, Franco. La corrupción en la emergencia: repercusiones sobre los derechos humanos. Revista IIDH, n. 72, p. 89-112, 2020.

5 GONZÁLEZ RÍOS, Isabel. La transparencia como principio vertebrador de la contratación pública: significado y problemas de articulación normativa. Revista de Estudios de la Administración Localy Autonómica, n. 12, p. 6-25, oct./mar. 2019.

6 DUQUE BOTERO, Juan David. Los principios de transparencia y publicidad como herramientas de lucha contra la corrupción en la contratación del Estado. Revista Digital de Derecho Administrativo, n. 24, p. 79-101, 2020.
} 
la Administración y el ciudadano, para que este último pueda participar en las decisiones administrativas, expresadas de tres formas distintas: el derecho a saber, el derecho al control y el derecho a participar en los mecanismos administrativos. El primero, se refiere al derecho del ciudadano a tener en cuenta el funcionamiento de la Administración, ya que está actuando a su servicio. El derecho de control, en cambio, que se refiere al segundo aspecto, está vinculado al "poder" que se le otorga al ciudadano, al conocer la Administración, con la posibilidad de verificar la legalidad del acto administrativo y la gestión. de dinero público. Esto, en consecuencia, conduce al tercer punto, que se refiere a la participación ciudadana en los mecanismos administrativos, es decir, el ciudadano ya no es un espectador. ${ }^{7}$

No se puede renunciar a la trasparencia como principio rector de la contratación pública con las excusas de la defensa de la libertad de mercado o la protección de propiedad intelectual como derecho fundamental. ${ }^{8}$ Por ello, es posible proponer aquí, que la adquisición de vacunas para combatir el virus de la COVID-19, requiere los mecanismos de vigilancia necesarios por el modo como se está comprometiendo la misma estabilidad estatal, tanto en su reputación política como en su estabilidad financiera a nivel nacional e internacional, afectando de manera directa el imaginario social del Estado Colombiano.

A continuación, se realizará un recuento de las publicaciones de algunos medios de comunicación colombianos - Las revistas Portafolio, que acude a la fuente oficial del Ministerio de Salud, y Semana, y el periódico El Tiempo- y de una publicación de BBC mundo, para plantear el problema en el contexto en el que se presentó. Todas las publicaciones son de enero de 2021, cuando, de modo muy desigual en ritmo y en suministros, ya había empezado el proceso de vacunación. El caso de Colombia en lo que respecta a la gestión de la pandemia es, como se verá, inquietante y para el caso de acatamiento del principio de la transparencia, altamente cuestionable.

En este apartado se deberían estar analizando los documentos discutidos por las partes como el fundamento contractual del proceso de adquisición, en lugar de tener que apelar a estas fuentes, a pesar de su relativa confiabilidad. Como tal, el siguiente itinerario es evidencia de que el principio de transparencia no está siendo debidamente atendido, por lo que se hace necesario hacer uso de la información disponible y, a partir del marcado contraste que hace con la necesidad de transparencia, proceder a hacer la crítica a un actuar que resulta lesivo para la institucionalidad misma de la democracia colombiana.

La publicación de la revista Portafolio del 13 de enero de 2021 es esclarecedora para el problema de la transparencia en el caso del proceso de adquisición de las vacunas. Según Portafolio, el ministro de Salud, Fernando Ruiz, afirmó que "ya suscribió con el mecanismo Covax, el contrato para adquirir vacunas para 10 millones de colombianos, equivalentes a 20 millones de dosis, con vacunas de dos dosis". El medio, añadió que el ministro "señaló también que ya se tienen los convenios con Pfizer y AstraZeneca, por 5 millones de vacunas de doble dosis con cada farmacéutica". Además "con Janssen, la compañía de biológicos de Johnson \& Johnson, por 9 millones, en este caso, para una dosis única". Según estas afirmaciones, lo prometido implica "un total de 29 millones de vacunas para cubrir inicialmente a la población priorizada en el Plan de Vacunación, de los 35 millones de personas que buscan inmunizar".

La cobertura, por tanto, parecía llegar a un número lo suficientemente alto como para confiar en que se trataría de un proceso masivo. La realidad sería muy distinta pasados algunos meses después de esas declaraciones, pues las promesas difirieron drásticamente de la realidad. Pero a este aspecto incumplido, el cual ya permite plantear varios interrogantes en la dirección de la inquietud por la transparencia, Portafolio añadió lo siguiente: “el Minsalud aclaró, además, que 'ningún país tiene posibilidad de comenzar las negociaciones previas de acceso a los contratos de compra de la vacuna sin suscribir un acuerdo de confidencialidad',

\footnotetext{
DA SILVA, Alice Rocha; SANTOS, Ruth MP. A influência do direito administrativo global no processo brasileiro de contratação pública à luz do princípio da transparência. Revista Brasileira de Políticas Públicas, v. 6, n. 2, p. 66-88, 2016.

8 ZAMBRANO, Virginia et al. O DIREITO À SAÚDE E À VIDA EM CONFRONTO COM O DIREITO À PROPRIEDADE INTELECTUAL DOS LABORATÓRIOS, NO ÂMBITO DA PANDEMIA DA COVID 19: A POSSIVEL QUEBRA DE PATENTES. Revista Juridica, [S.1.], v. 5, n. 62, p. 168 - 192, 2021.
} 
teniendo presente la información sensible que se está manejando". Y remata afirmando que, según el ministro. "si llegase a violarse esa confidencialidad, el país deberá atenerse a las sanciones y posible pérdida de la negociación y, por ende, de los biológicos”. Siendo lo anterior una amenaza con tintes de chantaje.

La cobertura prometida no se compadeció con la urgencia del suministro, pues para mediados de febrero, el país tenía, según la misma revista, citando fuentes oficiales, poco más de 33.000 vacunados. La comparación con Chile deja la gestión colombiana en una situación muy comprometida que no se exagera al llamársela ineficiente, al menos en lo que respecta a la cantidad de personas. Pero este aspecto contextual profundiza la inquietud de un término mencionado dos veces por el ministro que motiva la presente reflexión jurídica sobre la transparencia: confidencialidad. En particular teniendo en cuenta que, según la misma revista antes citada, "en medio de este debate, Portafolio conoció que a la fecha el presupuesto asignado para respaldar los acuerdos suscritos sería de $\$ 1,53$ billones, a partir de los montos incluidos en cuatro resoluciones del Ministerio de Hacienda”. La redacción es confusa y genera inquietud, pues el medio solo conoció una suposición, lo que indica que la información es poco confiable porque el monto indicado puede variar, posiblemente para hacerse más alto.

Es decir, que un rubro semejante, proveniente de los impuestos del país, se está invirtiendo en un proceso de negociación muy delicado, pero respecto al cual no se puede tener información porque no hay distinción plena y adecuada entre confidencialidad y falta de transparencia, lo cual ya fue advertido por la doctrina ${ }^{9}$. Los mismos medios emplean términos asociados con la falta de certeza, pues admiten que es solo eso lo que se sabe, implicando que la poca información disponible y la ausencia total de los documentos oficiales y legales no parecen producir sorpresa o inquietud, ni siquiera por el rubro. Durante la pandemia generada por el virus de la COVID-19, las farmacéuticas han logrado tener una posición dominante frente a muchos estados, pero esto no podía haber llevado a estos a renunciar a contrataciones transparentes, pues los dineros invertidos en la compra de vacunas son recursos públicos siempre y en toda circunstancia sujetos a controles.

La Corte Constitucional ha conceptuado respecto a la contratación teniendo en cuenta la cuantía (C004/17), basta con el monto involucrado en el costo de la compra de las vacunas para que la necesidad de mediar el control por la vía jurídica sea evidente. Es más, la misma fuente, que conviene citar aquí en extenso, explica el procedimiento en los siguientes términos:

"La entidad encargada de todo el proceso para la negociación, adquisición y logística de las vacunas es el Ministerio de Salud. Por medio de la Resolución 1270 de 2020 se creó un comité asesor para acompañar a la entidad en todo lo referente al proceso de inmunización, y a través del decreto 1258 de 2020 se conformó también la Instancia de coordinación y asesoría para el acceso a vacunas seguras y eficaces contra el coronavirus".

"En este proceso también interviene la Unidad Nacional para la Gestión del Riesgo de Desastres (Ungrd), que es la responsable de ordenar el gasto del Fondo Nacional de Gestión del Riesgo de Desastres, y dentro de este, la subcuenta para la Mitigación de Emergencias del Covid coordina los gastos de Minsalud para mitigar la pandemia, lo que incluye no solo el proceso de vacunación, sino también de ventiladores y material médico, entre otros".

"Los contratos de dicha subcuenta están definidos por la normativa del derecho privado, conforme a las leyes establecidas por el derecho civil o comercial. Si bien las resoluciones en las que se establecen los montos destinados son públicas, los acuerdos suscritos con las farmacéuticas son confidenciales". Sentencia C-145 de 2020

El problema jurídico aquí es evidente, pues el derecho privado resulta más generoso para los particulares que para el mismo Estado al poderse ocupar de las impresiones para hacer los ajustes necesarios ${ }^{10}$. En

\footnotetext{
9 MALARET, Elisenda. El nuevo reto de la contratación pública para afianzar la integridad y el control: reforzar el profesionalismo y la transparencia. Revista Digital de Derecho Administrativo, n. 15, p. 21-60, 2016

${ }^{10}$ HINESTROSA, FERNANDO. Teoría de la imprevisión. Revista de Derecho Privado, n. 39, p. 9-29, Jul./Dic. 2020.
} 
un contexto de mucha incertidumbre, gran parte de la cual se eliminaría con el suministro eficiente de las vacunas -con lo que el tema insistente de la economía tendría también la respuesta anhelada de reactivación total - y en el que está en juego la garantía de un derecho fundamental como es el de la salud - según lo consagra el Artículo 49 del Superior modificado por el Acto Legislativo No. 02 de 2009, artículo 1-, que la contratación se realice teniendo al derecho privado como fundamento jurídico, es perjudicial para el Estado pues se sacrifican muchos de los controles existentes para lo público.

Lo que desde la perspectiva del derecho civil negocial-contractual, el cual permite todo lo que no está expresamente prohibido, parece un punto de partida que debe darse por supuesto, resulta siendo, desde la perspectiva del derecho público, un inquietante problema de falta de control y de riesgos de ocultamientos cuestionable, pues los mecanismos de control en lo público son muy rigurosos. Es aquí donde la transparencia deviene en problema jurídico de reflexión, el cual ya fue propuesto desde perspectiva sociopolítica ${ }^{11}$, pues el contexto no deja claro, y por tanto hace cuestionable, que el régimen de una negociación tan importante desde lo económico, lo social y lo político, sea el privado.

Cualquiera de los elementos mencionados hasta aquí, habilita este cuestionamiento, en particular en un contexto doctrinal en el que también se ha resaltado el carácter transnacional de la transparencia ${ }^{12}$. No se trata de un problema como el de las sociedades de economía mixta y la complejidad de la determinación del régimen contractual a partir de porcentaje de aportes, sino de la negociación entre empresas farmacéuticas con mucho poder negocial por su posición dominante en el mercado en medio de la mayor crisis sanitaria de los últimos 100 años y el Gobierno de un Estado que se encuentra enfrentando un escenario con un nivel de complejidad mayor al acostumbrado. ${ }^{13}$

En este sentido otro medio, la revista Semana, en publicación del día 15 de enero del 2021, cita al presidente Duque afirmando que revelar los contratos contra la covid "tumbaría" la compra. El Presidente de Colombia emplea en este contexto el término coloquial tumbar, con lo que su discurso informal contrasta de modo drástico con otras retóricas presidenciales ${ }^{14}$ y con el compromiso de la comunicación apropiada ${ }^{15}$, para advertir que el proceso de contratación se arruinaría, implicando, por supuesto, que entonces no se contaría con el suministro de las vacunas. El 25 de enero, el Ministerio de Salud, en el Boletín de Prensa No 089 de 2021, insistió en esta postura, pues el ministro aseguró que "tanto para Colombia como para el resto de los países, las negociaciones son procesos muy complejos y en todos los países se han requerido acuerdos de confidencialidad, los cuales cobijan la información sobre los respectivos contratos".

Previamente, el 14 de enero, el periódico El Tiempo publicó una nota en la que expresa la inquietud de la confidencialidad, que parece convertirse en una excusa negocial para el secretismo, es decir, para aprovechar la necesidad de salvaguardar cierta información que es reservada para, junto con ella, no hacer públicos los detalles de la inversión de dineros que también son públicos y que, por tanto, exigen de una vigilancia ejercida desde la ciudadanía ${ }^{16}$. La nota cita a Camilo Enciso, director de Instituto Anticorrupción, quien aseguró que "la normativa vigente protege el secreto industrial y la propiedad intelectual, pero que nadie está pidiendo datos del compuesto o fórmula de las vacunas, sino del proceso contractual". Por eso, no se trata de un problema de la competencia ni de diseño de la contratación pública colombiana. Y el director añade:

\footnotetext{
11 VALENCIA-GRAJALES, José Fernando; MARÍN-GALEANO, Mayda Soraya. SARS-CoV-2 y la debacle del Estado, la justicia, la democracia, el capitalismo y el inicio de la era de la vigilancia. Ratio Juris, v. 15, n. 30, 2020.

12 VEGA DE HERRERA, Mariela. Aplicación de los principios de igualdad y transparencia en la contratación pública de España y de Colombia. Prolegómenos. Derechos y Valores, v. VIII, n. 16, p. 67-78, jul./dic. 2005.

13 GATTI, Franco. La corrupción en la emergencia: repercusiones sobre los derechos humanos. Revista IIDH, n. 72, p. 89-112, 2020.

14 ALEJANDRA VITALE, María. Discurso presidencial sobre el COVID-19. El caso de Alberto Fernández en Argentina. deSignis, v. 33, p. 113-125, Jul. 2020.

15 URBINA-MEDINA, Huníades; NOGUERA BRIZUELA, Dalmacia; LEVY MIZHARY, José; CARRIZO, Juan III; BETANCOURT, Adelfa. Comunicación efectiva y ética en casos de epidemias y pandemias. Archivos Venezolanos de Puericultura y Pediatría, v. 79, n. 4, p. 113-117, oct./dic. 2016.

16 SANDOVAL-ALMAZÁN, Rodrigo. Gobierno abierto y transparencia: construyendo un marco conceptual. Convergencia. Revista de Ciencias Sociales, v. 22, n. 68, p. 203-227, mayo/ago. 2015.
} 
"estos contratos tienen mucha información de interés, como, por ejemplo, las obligaciones de las partes, las garantías que dieron para cumplir el objeto del contrato, 'y nada de eso tiene que ver con el secreto industrial'. También afirmó que la ley 80 , que rige la contratación, establece el principio de transparencia y publicidad en todos los contratos que el Estado firme con los particulares”.

Esta exigencia no es nueva y se encuentra sustentada teórica, sociológica y políticamente ${ }^{17}$. Además, la nota incluye a Johnatan García, investigador de Dejusticia, quien "señaló que la regulación de la contratación exige que los contratos sean públicos y que incluso en las normas que han regido los contratos para emergencia sanitaria ha quedado claro que los contratos son públicos". Al respecto, el experto comentó lo siguiente según el periódico El Tiempo:

"Sin embargo, señaló que la ley permite las cláusulas de confidencialidad y las empresas pueden considerar que información como el valor de sus productos y la forma de distribución puede ser usada por su competencia. Señaló que en otros países se ha hablado con los laboratorios para flexibilizar la información e incluso dar acceso a representantes de la sociedad y órganos de control".

Este aspecto es importante porque se encuentra irresuelto, y satisfacer la transparencia es requisito de la estabilidad democrática ${ }^{18}$ y de proyección de la sostenibilidad ${ }^{19}$. El 28 de enero de 2021, la BBC hizo un diagnóstico de la situación en diversos lugares del mundo, y se puede plantear la hipótesis de que son las farmacéuticas -apoyadas por la economía del libre mercado y, por tanto, de la oferta y la demanda- las que tienen las ventajas para imponerle sus condiciones a los estados, pues el portal informa en su nota que hasta la Comisión Europea "se enfrenta al problema de hacer que las farmacéuticas cumplan con sus promesas". Pero la nota no es importante solo por la panorámica que fundamenta la hipótesis, sino que, a la luz de la dinámica económica, ser transparente parece organizacionalmente pernicioso para los negocios ${ }^{20}$.

El portal lo indica del siguiente modo: según el economista David Bardey, en conversación con la misma $\mathrm{BBC}$, dijo que "si hubiera transparencia en los precios de los medicamentos, 'sería más complicado para los laboratorios cobrar precios más altos a los países más ricos si estos pueden observar precios menores para otros países". Sin embargo, el mismo medio menciona a Jonathan García, esta vez como experto en salud pública en la Universidad de Harvard, quien aclara que "en EE. UU. 'esto no es nada nuevo; es frecuente que en los contratos entre los sistemas de salud de los países y las farmacéuticas se incluyan cláusulas de confidencialidad". El experto añade que "los laboratorios buscan fraccionar el mercado para poder negociar precios distintos con los distintos países". Y la BBC aclara que "esto les permite negociar con los países en función de sus recursos, ofreciéndoles precios más bajos a los países pobres o en desarrollo y exigiendo cantidades más altas a los más ricos". Pero es llamativo que no se mencionen las alternativas ofrecidas por el derecho privado internacional ${ }^{21}$.

Tampoco se tiene en cuenta lo abusivas que son las relaciones mercantiles que se sustentan en la oferta y la demanda que en condiciones normales generan tratos desiguales, pero que en medio de la mayor crisis sanitaria de los últimos 100 años ha evidenciado el egoísmo de los seres humanos. Los estados ricos acaparan más vacunas de las necesarias para cubrir sus poblaciones y los estados pobres esperan las migajas dejadas por los ricos.

\footnotetext{
17 UVALLE BERRONES, Ricardo. Fundamentos de la transparencia en la sociedad contemporánea. Revista Mexicana de Ciencias Politicas y Sociales, v. LXI, n. 226, p. 199-220, ene./abr. 2016.

18 SANDOVAL BALLESTEROS, Irma Eréndira. Hacia un proyecto “democrático-expansivo" de transparencia. Revista Mexicana de Ciencias Politicas y Sociales, v. LVIII, n. 219, p. 103-134, sep./dic. 2013.

19 GILLI, Juan José. La transparencia como objetivo del desarrollo sostenible. Ciencias Administrativas, n. 9, 2017.

20 ARELLANO GAULT, David. Transparencia desde un análisis organizativo: los límites del nuevo institucionalismo económico y las "fallas de transparencia". Revista del CLAD Reforma y Democracia, n. 40, p. 53-80, feb. 2008.

21 CASTRO DE CIFUENTES, Marcela. Los contratos normativos y los contratos marco en el derecho privado contemporáneo. Revista Estudios Socio-Jurídicos, v. 21, n. 1, p. 121-150, Ene./Jun. 2019.
} 
Sin embargo, a diferencia del economista, el experto en salud "cree que los argumentos a favor de la transparencia ganan valor en el contexto de la pandemia", en particular por los riesgos de corrupción" ${ }^{22}$, que aumentan debido a las presiones añadidas por la pandemia. Y la BBC cita al experto directamente: "Estamos hablando de una emergencia sanitaria global, de algo que sucede cada 100 años, ante lo que uno esperaría que el sistema utilizara mecanismos mucho más transparentes y buscara un esquema más cooperativo". La situación puede parecer inédita, pero fue prevista ${ }^{23}$. Por lo que asegura que "en cambio vemos que se sigue buscando un mercado monopólico y mantener ventajas en los precios", lo cual implica el reto de delimitar las aspiraciones de lucro de las farmacéuticas a partir de un criterio al menos médico y no solo de oferta y demanda. ${ }^{24}$

El contexto ofrecido por los medios de comunicación indica, por tanto, uno de los aspectos del debate jurídico: la tensión entre los intereses de la economía privada y los intereses de la salud pública en un contexto extraordinario, pero no imprevisto, como el de la pandemia por la COVID-19. ${ }^{25}$

\section{Normativa y jurisprudencia colombiana respecto a la Emergencia}

El análisis de las fuentes normativas que habilitaron las facultades extraordinarias por el caso de emergencia permite determinar la posibilidad de que se haya presentado una omisión o una actuación cuestionable respecto a la falta de información oportuna y confiable respecto al caso concreto de la negociación para adquirir las vacunas de la cóvid-19. Por eso conviene señalar los elementos relevantes tanto del Decreto 417 de 2020 como de la sentencia C-145 de 2020 respecto a las potestades otorgadas al Presidente para hacer frente de modo adecuado a la situación anormal con motivo de la pandemia.

El Decreto 417 de 2020, publicado el 17 de marzo de 2020, "se declara un Estado de Emergencia Económica, Social y Ecológica en todo el territorio Nacional". Es llamativo que el Decreto se enfoca en sus presupuestos fácticos en la salud pública y en los aspectos económicos. No hay mención de vacunas, lo cual se podría considerar una omisión notable debido a que no es posible inferirla de la palabra mitigación, la cual se enfoca de modo predominante en las consideraciones e inquietudes respecto a la economía. La implicación que permite hacer la hermenéutica jurídica no puede llevar la posibilidad de interpretar el texto del Decreto hasta tal subsunción. Por asombroso que pudiera ser, el Gobierno no tuvo proyección respecto a una posible solución de la crisis en la forma de vacunas.

De modo que se le puede reprochar en este punto que no hubo una proyección acorde con lo que los mismos organismos internacionales mencionados en el Decreto, específicamente la OMS, ya advertían al indicar que se trataba de un evento de carácter internacional: que la probabilidad de que la pandemia se extendiera era muy alta y que no se debían tomar solo medidas de choque. El Gobierno no tuvo en cuenta el útil principio de planeación, como principio rector de la actividad del Estado y lúcidamente propuesto por el Consejo de Estado en diversa jurisprudencia. Y el atenuante de una posible eficiencia respecto a las medidas que se debían tomar de modo inmediato es muy débil, pues la asesoría de expertos epidemiólogos hubiese ofrecido importantes claridades y recomendaciones a la hora de hacer esa proyección al mediano plazo. La preocupación central del Decreto subordina la salud pública, la cual ya fue resaltada por la doctrina como el criterio constitucional prevalente ${ }^{26}$ a los aspectos netamente económicos. Las prioridades contras-

\footnotetext{
22 SCHELLER D’ANGELO, André; SILVA MAESTRE, Shirly. La corrupción en la contratación pública: operatividad, tipificación, percepción, costos y beneficios. Revista VIA IURIS, n. 23, p. 1-36, jul.dic. 2017.

23 OSORES PLENGE, Fernando; GÓMEZ BENAVIDES, Jorge; SUAREZ OGNIO, Luis; CABEZAS SÁNCHEZ, César; ALAVE ROSAS, Jorge; MAGUIÑA VARGAS, Ciro. Un nuevo virus A/H1N1, una nueva pandemia: Influenza un riesgo permanente para una humanidad globalizada. Acta Médica Peruana, v. 26, n. 2, p. 97-130, 2009.

24 .DA SILVA, Alice Rocha; SANTOS, Ruth MP. A influência do direito administrativo global no processo brasileiro de contratação pública à luz do princípio da transparência. Revista Brasileira de Políticas Públicas, v. 6, n. 2, p. 66-88, 2016.

25 DADICO, Claudia María. Epidemias, pandemias e o ódio: caminhos para a governamentalidade da pandemia da Covid-19. Publicum, v. 6, n. 1, 2020.

${ }^{26}$ CHACÍN FUENMAYOR, Ronald; VILLA-VILLA, Sandra; BERROCAL-DURAN, Juan Carlos. Interpretación democrática de la constitución colombiana en tiempos de crisis (pandemia COVID-19). Utopía y Praxis Latinoamericana, v. 25, n. Esp.8, 2020
} 
tan marcadamente con el secretismo y opacidad que, como se verá en el apartado siguiente, rodeó de las negociaciones, a menos que se proponga que la mentalidad negocial era el derecho privado.

Se puede entender el marcado interés del Gobierno Nacional en el aspecto económico y el cuidado de las finanzas públicas, pero no su desdén en la conservación de los límites y controles existentes para la contratación pública establecidos en leyes como la 80 de 1993. El proceder del mismo Gobierno en el proceso de adquisición de las vacunas hace un marcado contraste con el interés que manifiesta el Decreto en ocuparse predominantemente de la economía de mercado. Si se tiene en cuenta que el documento legal afirma que "los choques que afectan los mercados financieros y laborales suelen tener efectos profundos y prolongados que deterioran el crecimiento, el bienestar de la sociedad y el empleo", el principio de planeación no necesariamente excluía al de transparencia. Es posible que el primero se pudiera asociar con la siguiente afirmación contenida en el Decreto:

"La adopción de medidas de rango legislativo, autorizadas por el Estado de Emergencia, buscan fortalecer las acciones dirigidas a conjurar los efectos de la crisis, así como a mejorar la situación de los contagiados y evitar una mayor propagación del COVID-19. No obstante, dado que la magnitud de la llegada del COVID-19 a Colombia no ha sido dimensionada en su totalidad, las medidas que se anuncian en este decreto no agotan los asuntos que pueden abordarse en ejercicio de las facultades conferidas por el estado de excepción, lo que significa que en el proceso de evaluación de los efectos de la emergencia podrían detectarse nuevos requerimientos y, por tanto, diseñarse estrategias novedosas para afrontar la crisis".

Sin embargo, el Decreto debió mencionar el principio de transparencia o hacer alusión a él de modo reconocible o verificable. La cita realmente deja abierta una categoría discrecional excesivamente abierta que debió reprocharse en el control realizado en la sentencia que se analizará a en el apartado siguiente. No hay ningún contorno definido respecto a cuáles podrían ser esas estrategias novedosas, así que hay motivos para considerar que la incertidumbre producida por la llegada de la pandemia no podía permitir que se propusiera una alternativa tan vaga como la anterior, y menos en un Decreto que tiene tan claro la doble motivación de la salud pública y de la estabilidad de la economía. Los aspectos sociales y ecológicos se mencionan de modo periférico, marcadamente indirecto y en asociación directa con la motivación del Decreto.

Adicionalmente a lo anterior, hay dos aspectos de la justificación que llaman poderosamente la atención. La primera es que el siguiente pasaje, el cual expone la necesidad de las atribuciones extraordinarias por insuficiencia de las ordinarias, enfatiza en el aspecto económico de la emergencia, hasta tal punto, que vuelve simbólicos los aspectos sociales y ecológicos:

"ante la insuficiencia de atribuciones ordinarias con las que cuentan las autoridades estatales para hacer frente a las circunstancias imprevistas y detonantes de la crisis económica y social generada por la pandemia del nuevo Coronavirus COVID-19, se hace necesario adoptar medidas extraordinarias que permitan conjurar los efectos de la crisis en la que está la totalidad del territorio nacional, en particular, aquellas que permitan acudir a mecanismos de apoyo al sector salud, y mitigar los efectos económicos que está enfrentando el país".

La segunda, que resulta inquietante, declara la insuficiencia de un conjunto del derecho positivo vigente colombiano que se puede interpretar de modos marcadamente diferentes: primero, como una insuficiencia que necesita de medidas que la complemente, o, segundo, como una insuficiencia que puede prescindir de tal normativa:

"se hace necesario por la urgencia y gravedad de la crisis y por la insuficiencia de los mecanismos jurídicos ofrecidos, entre otros, en la Ley 100 de 1993 - Por la cual se crea el Sistema de Seguridad Social integral, la Ley 1122 de 2007 - Sistema General de Seguridad Social en Salud, Ley 1438 de 2011, Ley 80 de 1993, el Decreto 663 de 1993 - Estatuto Orgánico del Sistema Financiero y el Decreto 111 de 1996 Estatuto Organice del Presupuesto, recurrir a las facultades del Estado de Emergencia con el fin de dictar decretos con fuerza de ley que permitan conjurar la grave crisis generada por el nuevo Coronavirus Covid-19 debido a la propagación y mortalidad generado por el mismo, el pánico por la propagación y las medidas de contención decretadas por cada Estado para evitar una mayor propagación”. 
Es decir, que se podrán promulgar decretos con fuerza de ley que eviten la mayor propagación que, eventualmente, terminó presentándose, y que, en caso de que el Presidente lo considere necesario, presuma la insuficiencia particularmente de la Ley 80 de 1993 que contiene todas las exigencias de la contratación estatal. De ahí que el reproche fundamental al Decreto se puede plantear del siguiente modo: las facultades extraordinarias concedidas al Presidente, con motivo del estado de emergencia económica, social y ecológica por sanidad no implica la eliminación de controles y vigilancia, y menos la inaplicación de los principios. Y si bien no lo expresa taxativamente, la alternativa de hacer tal lectura queda abierta. Y la falta de información respecto a la negociación para la compra de las vacunas, aspecto que se tratará más adelante, lo hace evidente.

Por su parte, en la Sentencia C-145 de 2020 realiza el control de constitucionalidad del Decreto mencionado. Una cuestión oportuna de la exequibilidad del Decreto mismo es, propiamente, la insuficiencia de las facultades ordinarias, aspecto que fue mencionado por uno de los ciudadanos intervinientes como parte del proceso mismo de la determinación del estatus de consistencia del Decreto en cuestión con los mandatos constitucionales. El concepto es el siguiente: "Falta argumentación y claridad en los motivos por los cuales a través de potestades ordinarias el Gobierno no puede hacer frente a la pandemia". Es decir, que tal vez no se trató con el debido cuidado la suposición ingenua de que, posiblemente, los mecanismos ya existentes tenían la competencia suficiente para tomar las medidas a que hubiera lugar, como si tuviera algún carácter indudable la afirmación de que situaciones extraordinarias exigieran medidas extraordinarias y, por tanto, facultades extraordinarias. No se puede pasar por alto que la restricción de derechos durante los diferentes confinamientos a la que fue sometida la población colombiana se hizo mediante normas ordinarias y competencias dadas por el Condigo Nacional de Policía (ley 1801), mientras que los poderes excepcionales fueron usados especialmente con fines económicos. Cabe, por tanto, hacer la pregunta de si el Gobierno debió primero verificar las vías ordinarias para llevar a cabo la toma de medidas necesarias para enfrentar el reto. Es decir, que queda planteada la cuestión de sí se trató de una medida viciada por extralimitación de funciones al no requerir de la declaratoria de un estado de emergencia. Sin embargo, en la sentencia comentada, la Corte Constitucional conceptúa del siguiente modo:

"la Corte quiere poner en evidencia que, en los 28 años de vigencia de la actual Carta Política, no se había presentado una crisis de las proporciones que ahora materializa la pandemia del Covid-19, y por tanto ello obliga el aplicar un nivel de intensidad que entienda tan especiales vicisitudes y particularidades. Habrá de ser un juicio atenuado, en todo caso distinto, que de una manera más adecuada, oportuna y eficaz valore las circunstancias reales que propiciaron la declaratoria de esta emergencia”.

Y añade:

"Los sucesos que exponen de manera más evidente al país a una grave calamidad sanitaria y que materializan de un modo claro perturbaciones y amenazas al orden económico, social y ecológico, pueden aparejar para el ejecutivo un mayor margen de apreciación para declarar el estado de emergencia, pero además para la escogencia de los remedios y soluciones que permitan una vuelta pronta a la normalidad".

Así que considera que, al tratarse de una situación inédita, la vía ordinaria es insuficiente para enfrentarla.

Por su parte, la Universidad Nacional de Colombia fue mucho más severa, e hizo eco de las inquietudes planteadas en el apartado anterior: "se ha perdido toda sensibilidad frente a los derechos humanos y fundamentales del constitucionalismo moderno", por lo que el Decreto no atiende los mandatos del Superior. Este concepto es útil para dimensionar el sentido de la Sentencia, la cual le confiere exequibilidad al Decreto, es decir, que es acorde con la Constitución. La Corte Constitucional colombiana afirma que "Como se trata de una situación extraordinaria donde la ley no es aprobada por el legislador, la Carta Política a su vez impone una serie de limitaciones, de los cuales se deriva la interpretación restrictiva de las facultades del Gobierno Nacional como única opción compatible con la democracia constitucional”, según lo cual, el reproche de la Universidad Nacional sería incorrecto. 
No obstante, el caso particular de la falta de publicidad y, por tanto, de transparencia en el caso de las negociaciones para la compra de las vacunas, expresa que, al menos lo que respecta a la vigilancia, es una interpretación restrictiva de las facultades que fue desatendida. De ahí que en el apartado que sigue la fuente de análisis no sean documentos que proporcionen la información necesaria para tal efecto, sino las referencias que los medios pudieron ofrecer en el contexto del debate mismo que motiva esta reflexión crítica. El anterior análisis se enfoca en el Decreto 417 de 2020, el cual declara el estado de emergencia por primera vez con motivo de la covid-19, pero se deja constancia que se presentó una segunda declaratoria de Emergencia mediante el Decreto 637 del 6 de mayo de 2020, y fue también declarado exequible por la Sentencia C-307 de 2020 de la Corte Constitucional de Colombia.

Ambas providencias advierten que, en virtud de la misma normativa vigente, la declaratoria de estado de emergencia no desmonta los mecanismos de vigilancia, pero resulta innegable que su operatividad en la práctica resultó drásticamente perjudicada. Estas normas, con motivo de la disponibilidad de vacunas en el mercado, llevó a que, con un sentido de urgencia análogo al del estado de emergencia, el proceso de negociación para la adquisición de las vacunas careciera de la transparencia de la que ha requerido como proceso, en el que están comprometidos una enorme cantidad de recursos públicos.

Es importante señalar aquí la incertidumbre normativa que hay después de esos decretos. La Presidencia de la República solo podía declarar otro estado de emergencia. Pero el problema jurídico que se presenta aquí es que después de este segundo decreto de mayo de 2020, en el que se declara una nueva Emergencia, el rastreo del fundamento normativo se hace complejo porque los Decretos no están disponibles en la página web que el Gobierno financió y destinó para tal efecto. Queda abierto aquí el interrogante respecto a la legitimidad de todas las actuaciones gubernamentales después de culminar el período indicado en los decretos mencionados.

En efecto, se pueden plantear interrogantes al respecto que se vinculan con la transparencia, dentro de los cuales interesa aquí el significado que tiene la falta de información acerca de los términos de las negociaciones que el Gobierno adelantó con las farmacéuticas para, en el contexto asumido, pero sin claridad jurídica, de la Emergencia Sanitaria, adquirir las vacunas para cincuenta millones de colombianos. La Emergencia otorga ciertas facultades al Presidente que de ninguna manera suprimen la necesidad de vigilar tales actuaciones. Sin ello, la posibilidad de prevenir o evitar posibles perjuicios a lo público, en particular al dinero involucrado en la compra y la garantía del derecho a la salud de la población involucrada, quedan a merced de interacciones que, en el contexto del derecho privado, están plenamente legitimadas, pero que, en el contexto del derecho público, derogan de facto la necesidad y exigencia de aplicar instrumentos de vigilancia. Es decir, que la transparencia deja de ser un principio aplicable en virtud de la elección de un contexto normativo que es discutible.

Por tanto, de la incertidumbre mencionada respecto a los decretos que mantienen vigente la Emergencia al menos desde junio de 2020 se elige para una caracterización más detallada el interrogante respecto a la ausencia de información sobre el proceso de contratación entre las farmacéuticas y el Gobierno Colombiano. Ante esa carencia de información, que la doctrina indica como inadmisible en tiempo de la cóvid-19 la hipótesis propuesta reduce a un Gobierno a ser el igual en términos negociales de una empresa multinacional. ${ }^{27}$ A ese respecto se extraerán algunas consecuencias en la conclusión de este artículo.

27 BRULL-GONZÁLEZ, Maribel. Sistema de información y comunicación para el enfrentamiento de las comunidades a desastres naturales, epidemias y pandemias. Ciencia en su PC, v. 1, n. 3, p. 1-17, Jul./sep. 2020. 


\section{Fundamento normativo del principio de transparencia.}

La propuesta de este artículo se enfoca en las condiciones del proceso que plantean inquietudes respecto a la aplicación del principio de transparencia, bajo el entendido de que las facultades extraordinarias con motivo de la emergencia debida a la COVID-19 le otorgó mayor margen de maniobra al ya amplio margen que tiene el presidencialismo colombiano, pero que no eliminó los mecanismos de vigilancia y control de sus actuaciones, pero particularmente las de vigilancia, las cuales dependen de la publicidad de la información respecto a los procesos y en los cuales se funda la garantía del principio de transparencia. Tales inquietudes ya fueron propuestas por la reflexión científica al respecto, y en los siguientes términos:

“La 'carrera' por las vacunas para la cóvid-19 expone las deficiencias del ecosistema de innovación médica que hace negocios como si tal cosa, impulsada por intereses económicos y no por los resultados en salud. En lugar de motivar la inteligencia colectiva, se apoya en la competencia entre vacunas privadas y permite que se rebajen los estándares de seguridad y eficacia, con lo que se pone en riesgo la salud de la población y se socaba su confianza" 28 (traducción propia).

Es decir, que el contexto de la COVID-19 no es uno en el que se puedan seguir haciendo negocios como si tal cosa, como si el mercado funcionase independiente y al margen de regulación. Esto implica una aplicación de políticas y de disposiciones negociales muy distintas de parte del Gobierno. Seguir permitiendo que el mercado se autorregule es una postura pasiva y aberrante que es inadmisible cuando se está enfrentando una pandemia. El comportamiento del mercado de las vacunas a nivel global ha estado marcado por un déficit ético, en el proceso de negociación entre los estados y las farmacéuticas y en su adquisición se dieron prácticas abusivas donde los países ricos acapararon más vacunas de las que necesitaban. Prevaleció el ánimo de lucro de los laboratorios sobre el derecho a la vida de los habitantes de los países más pobres. No estuvimos a la altura de enfrentar una crisis global y se evidenció el egoísmo y la avaricia humana. No ponerles controles a las farmacéuticas ha llevado a una situación que nos debería dar vergüenza como humanidad. La mano invisible propuesta por Smith ha demostrado su inoperancia en un momento donde las farmaceutas han buscado el lucro mientras ser perdían muchas vidas humanas ${ }^{29}$.

Lo que resulta llamativo de este planteamiento es que se puede objetar la disposición de las farmacéuticas, que parecen estar interesadas solo en sacar el máximo provecho de la crisis generada por la pandemia, como si se pudiera presumir sin dudas que en los negocios no importa nada más que el aumento de las ganancias, pero realmente, las farmacéuticas también tienen una responsabilidad social empresarial respecto a la salvaguarda de un derecho fundamental que no riñe con su ánimo de lucro ${ }^{30}$.

Otro aspecto llamativo que conviene mencionar es la relación entre confidencialidad, secreto empresarial, transparencia y un posible secretismo, entendiendo esto último como una renuencia cuestionable y con apoyo jurídico débil para no revelar condiciones polémicas o reprochables del contrato. El contraste tan marcado entre los regímenes privado y público respecto a la transparencia debería llevar a que se resalte que por el hecho de que hay un privado, en este caso una empresa farmacéutica, como parte de la contratación para la adquisición de las vacunas, se trata de un asunto público, como sí se planteara una condición sobreviniente de las farmacéuticas -las cuales son negocios sumamente exitosos ${ }^{31}$ - como prestadoras de un servicio público básico y que no se pueden sustraer al escrutinio de sus actuaciones a la luz de lo público y de los controles que se asocian con ello.

\footnotetext{
${ }_{28}$ TORREELE, E. Business-as-Usual will not Deliver the COVID-19 Vaccines We Need. Development (Basingstoke), v. 63, n. 2-4, p. 191,2020

29 SMITH, Adam. La riqueza de las naciones, libro IV, cap. II, p. 456-457.

30 SANTORO, M., SHANKLIN, R. Human rights obligations of drug companies. Journal of Human Rights, v. 19, n. 5, p. 557-567, 2020.

31 PECETTA, S., FINCO, O., SEUBERT, A. Quantum leap of monoclonal antibody (mAb) discovery and development in the COVID-19 era. Seminars in Immunology, 50, art. n. 101427, 2020.
} 
El Principio de Transparencia es un valor del Derecho Administrativo Global, por su reconocimiento por parte de las instancias globales como indispensable para el proceso de contratación pública, bien sea por ser una herramienta de gobernanza global, o porque es un mecanismo para aumentar la rendición de cuentas (responsabilidad) de la Administración Pública. ${ }^{32}$ Por ello, la transparencia, la publicidad y el control cobran aún más importancia, principalmente porque situaciones de crisis como ésta implican un cierto grado de "relajamiento" en el rigor de la contratación pública, implicando acciones y toma de decisiones, que exigen una mayor fiscalización por parte de la sociedad y responsabilidad de los gestores públicos; con principios éticos para evitar la corrupción. ${ }^{33}$

Con el acaecimiento de la pandemia la posición privilegiada de multinacionales farmacéuticas es clara, no solo porque se está haciendo énfasis en las condiciones de ganancia financiera y las opciones que les quedan abiertas para situaciones futuras ${ }^{34}$ sino porque la responsabilidad que tienen como proveedores de servicios y sus posibles desatenciones que escapan a cualquier supervisión y sanción. Es un fenómeno de carácter global que antepone las patentes al servicio ${ }^{35}$.

Lo anterior genera inquietudes que se comprenden a la luz de la abundante normativa colombiana sobre la transparencia. Basta con un compendio no definitivo de leyes que siguen vigentes, las cuales conviene mencionar como el trasfondo jurídico de una interpretación que se va a proponer respecto a la funcionalidad que se le concede al principio de transparencia: Ley 80 de 1993, Ley 1150 de 2007, Ley 1474 de 2011, Decreto Ley 019 de 2012, Ley 1882 de 2018, Decreto Reglamentario 1082 de 2015, Ley 18822018 Transparencia en la contratación pública, Ley 1849 de 2017 Código de Extinción de Dominio para combatir la corrupción e incentivar la denuncia ciudadana, Ley 1828 de 2017 del Código de ética y disciplinario del Congresista, Ley 1778 de 2016 del Soborno a servidores públicos extranjeros en transacciones comerciales internacionales, Ley 1757 de 2015 del Derecho a la participación democrática, Ley 1762 de 2015 de Contrabando, lavado de activos y evasión fiscal, Ley 1712 de 2014 de Transparencia y derecho de acceso a la información pública Nacional, Ley 1474 de 2011 del Fortalecimiento de los mecanismos de prevención, investigación y sanción, Ley 412 de 1997 de la Definición de actos de corrupción, Ley 190 de 1995 de la Erradicación de la corrupción administrativa, Decreto 1499 de 2017 de la Transparencia, acceso a la información pública y lucha contra la corrupción, Decreto 1686 de 2017 de las Comisiones Regionales de Moralización, Decreto 124 de 2016 del Plan Anticorrupción y de Atención al Ciudadano, Decreto 1081 de 2015 de la Transparencia y derecho de acceso a la información pública Nacional, Decreto 41702011 Creación Agencia Nacional de Contratación pública, y Ley 1712 de 2014 o de Transparencia y del Derecho de Acceso a la Información Pública Nacional.

¿Qué significa esta proliferación normativa, inevitablemente, genera una tendencia entrópica, es decir, de caída en el desorden? ¿Tantas normas que buscan la transparencia en las actuaciones públicas quedan suspendidas en tiempo de pandemia? Pues bien, una propuesta de interpretación que se puede proponer aquí es que, además de esta objeción a la cantidad excesiva que parece necesitar de tipos particulares de control dependiendo del tipo de interacción en lugar de proponer un dispositivo que se pueda aplicar en cualquier escenario en el que sea necesario determinar la transparencia a través de la vigilancia, es que hay una tendencia a ver la transparencia como principio operativo en los mecanismos de control. No en vano se la ve en esta normativa mencionada asociada estrechamente al fenómeno general que recibe el nombre de corrupción. Este desplazamiento funcional afecta profundamente la posibilidad de que la vigilancia preven-

\footnotetext{
32 DA SILVA, Alice Rocha; SANTOS, Ruth MP. A influência do direito administrativo global no processo brasileiro de contratação pública à luz do princípio da transparência. Revista Brasileira de Políticas Públicas, v. 6, n. 2, p. 66-88, 2016.

33 DA CONCEIÇÃO LIMA, Luciana Cristina, et al. Compliance em tempos de calamidade pública: análise sobre a flexibilização da transparência de dados e informações durante o enfrentamento da COVID-19 no Brasil. Revista Brasileira de Políticas Públicas, v. 11, n. 1, 2021.

34 BILLINGTON, J.; DESCHAMPS, I.; ERCK, S. C.; GERBERDING, J.L.; HANON, E.; IVOL, S.; SHIVER, J.W.; SPENCER, J.A.; VAN HOOF, J. Developing Vaccines for SARS-CoV-2 and Future Epidemics and Pandemics: Applying Lessons from Past Outbreaks. Health Security, v. 18, n. 3, p. 241-249, 2020.

35 SYED, S. Incorporation of competition-related TRIPS flexibilities in the domestic law: A case study of India. Journal of World Intellectual Property, v. 23, n.1-2, p. 2-20, 2020.
} 
ga posibles actuaciones jurídicamente cuestionables o perjudiciales para los intereses del Estado. La entrópica normativa y la situación excepcional de la pandemia no exime al Gobierno de su obligación de aplicar el principio de transparencia en el proceso de negociación, adquisición de vacunas y puesta en marcha del proceso de vacunación y de no ser así se generan unas circunstancias propicias para actos de corrupción.

En lo que respecta a la jurisprudencia de Altas Cortes colombianas sobre la transparencia establece un enlace predominante con la corrupción, término general con el que se designan simultáneamente algunos de los delitos que el Código Penal Colombiano asocia con comportamientos que aprovechan irregularmente lo público para el lucro privado y ciertos comportamientos que, sin ser legalmente reprochables, se pueden cuestionar desde perspectivas éticas o políticas. Es corrupto todo aquél que, investido con algún tipo de poder o prerrogativa, se desentiende intencionalmente de la labor que le fue encomendada o la manipula con el solo propósito de emplearla en función de sus intenciones particulares. ${ }^{36}$

La Corte Constitucional ha proferido algunas providencias importantes al respecto, como la C-193 del 2011, la cual crea un Comité de Ética y Transparencia, y las C-620 y C-1016 de 2012 las cuales tratan la relación del principio de transparencia con la eficiencia en la contratación pública. La Corte Suprema de Justicia poco lo emplea. La hipótesis de trabajo que se puede proponer es que el principio de transparencia es una exigencia asociada predominantemente con el despliegue público de las interacciones jurídicas. Esto deja abierta la opción para preguntarse si entonces en lo privado no es necesario atender este principio con tanto celo como se lo atiende en los asuntos que involucran la actuación del Estado.

No se trata de un tema menor ni subsidiario. Con la flexibilización en la que el derecho ha entrado, y en el modo como sus dinámicas se hacen cada vez más volátiles y transitorias, este cambio y diferencia en la mentalidad de cada entorno jurídico es inquietante cuando se trata de los regímenes de libre mercado la normativa que los debe determinar. Es aquí donde esta discusión sobre el principio de transparencia deja de ser abstracta y adquiere contornos y características muy definidas y abocadas al asunto concreto de su aplicación en procesos que tienen influencia y consecuencia en la cotidianidad de la ciudadanía.

En efecto, elegir el régimen privado para regular las actividades que involucran dineros públicos es en sí mismo un reto para la pregunta por la aplicación del principio de transparencia. Si lo que se debe hacer ante la corrupción es evitarla antes que detectarla o sancionarla, entonces la vía positiva de la aplicación del principio de transparencia debería llevar a que se aplique el régimen que tenga controles adecuados. Este es un debate que, al poner en el orden de prioridades a la inversión y al capital, abre un contexto de evidente conflictividad con el riesgo de corrupción. Este término, que no es jurídico sino sociopolítico, es particularmente llamativo porque expresa la apropiación indirecta de un conjunto de tipos penales que establecen la dimensión de aplicabilidad del principio de transparencia que parece ser el correcto o al menos el esperado. Si el ordenamiento jurídico busca imponer parámetros mínimos de transparencia en la contratación pública para disminuir actos de corrupción, eliminarlos y/o eludirlos podría llevar a mayor posibilidad de que éstos se presenten. La transparencia, en consecuencia, es también un elemento obligatorio que permea a toda la Administración, ya sea en la protección de los derechos del administrador, en la organización administrativa o en la prestación de servicios y políticas públicas. ${ }^{37}$

En el contexto particular de la jurisprudencia de Altas Cortes en Colombia, conviene tener lo anterior como instrumento de interpretación de las actuaciones, pues entre las actuaciones que promueven el no dejar que se sepa nada y las actuaciones que promueven el poner todo en evidencia para que no se logre reconocer nada, hay un vasto e inestable contexto en el que predominan la sospecha y la incertidumbre $y$, debido a esta negatividad de la aplicación del principio, es la misma estatalidad la que resulta profundamente

\footnotetext{
36 LAURELL, Asa Cristina. Las dimensiones de la pandemia de Covid-19. El trimestre econ, Ciudad de México, v. 87, n. 348, p. 963984, dic. 2020.

37 DO AMARAL, Marcelo Quevedo. A transparência da política monetária e a sua limitação aos objetivos constitucionais. Revista Brasileira de Politicas Públicas, v. 8, n. 1, p. 706-724, 2018.
} 
perjudicada en los tres aspectos que se van a asociar de modo explícito y decidido con la transparencia: la credibilidad, la legitimidad y la confianza en el Estado.

\section{5 ¿Se puede sacrificar la transparencia en aras de la confidencialidad?}

Los impedimentos para poder conocer información la cual, debido a la naturaleza del interés de procesos de contratación como el de la adquisición de las vacunas para la cóvid-19 por parte del Gobierno colombiano, es de necesario conocimiento para que se pueda realizar el ejercicio de vigilancia, presenta un debate con la confidencialidad en el libre mercado, es decir, la potestad de las partes en reservarse información que consideran determinante para la salvaguarda de sus intereses negóciales. En el período que va entre los meses de noviembre de 2020 y abril de 2021 se tienen solo notas de prensa al respecto. No hay disponible ningún documento de negociación. La razonabilidad de esta medida de confidencialidad -discutible pues denota falta de transparencia- plantea el interrogante de la causa de esta y permite plantear una hipótesis de trabajo que se puede elaborar desde una perspectiva de crítica jurídica.

Las empresas farmacéuticas que suministraron las vacunas tenían, en esta ausencia de información, una posición dominante y privilegiada. La hipótesis es, por tanto, que la dinámica de interacción negocial, una vez empezaron a llegar las vacunas a Colombia, es la del derecho privado: por un lado, las farmacéuticas tienen un producto que, por el otro, el Gobierno colombiano tiene interés en adquirir. Ahora se trata de un Gobierno que es cliente de una parte negocial que tiene las potestades de imponerle condiciones, y esto plantea el problema triple de la legitimad, la credibilidad y la confianza de un Estado que se reduce a la condición de una de las partes del sinálagma contractual.

Lo anterior despierta la inquietud fundamental de este artículo. Se trata de explicar y comprender, es decir de interpretar, el significado de la indisponibilidad de una información que, desde la perspectiva del derecho público, se asume de acceso inmediato. Este aspecto contextual profundiza la inquietud de un término mencionado dos veces por el Ministro de Salud y Protección Social de Colombia que motiva la presente reflexión jurídica sobre la transparencia: confidencialidad. En particular teniendo en cuenta que, según la revista Portafolio, la cual hace eco de lo que dicen muchos medios semejantes, "en medio de este debate, Portafolio conoció que a la fecha el presupuesto asignado para respaldar los acuerdos suscritos sería de $\$ 1,53$ billones, a partir de los montos incluidos en cuatro resoluciones del Ministerio de Hacienda". La redacción de esta nota es confusa y genera inquietud, pues el medio solo conoció una suposición, lo que indica que la información es poco confiable porque el monto indicado puede variar, posiblemente para hacerse más alto.

Es decir, que un rubro semejante, proveniente de los impuestos del país, se está invirtiendo en un proceso de negociación muy delicado y de suma importancia, pero respecto al cual no se puede tener información porque no hay distinción plena y adecuada entre confidencialidad y falta de transparencia. Los mismos medios emplean términos asociados con la falta de certeza, pues admiten que es solo eso lo que se sabe, resaltando que la poca información disponible y la ausencia total de los documentos oficiales y legales no parece producir sorpresa o inquietud, ni siquiera por la gran cantidad de recursos públicos invertidos. Pero si la Corte Constitucional ha conceptuado respecto a la contratación teniendo en cuenta la cuantía (C-004/17), basta con el monto involucrado en el costo de la compra de las vacunas para que la necesidad de mediar el control por la vía jurídica sea evidente.

Sin embargo, la información hasta el momento en que se termina de escribir este artículo nunca estuvo disponible. Las dosis empezaron a llegar a Colombia, de modo que el Gobierno Colombiano cerró los contratos de suministro con las farmacéuticas sin que se tuviese conocimiento público de las condiciones impuestas en ellos. Se trató de un negocio con todas las características de la teoría del contrato privado a pesar de que una de las partes es el Gobierno de un Estado soberano y que la otra es una empresa. El aspecto 
sociopolítico de que se trata de un Gobierno de un país emergente y de que la empresa es una multinacional con posición dominante puede ser una explicación desde la perspectiva de la sociología jurídica. Pero, desde la perspectiva de la discusión jurídica stricto sensu que se propone en este artículo, tal caracterización solo insiste en la necesidad de haber aplicado las condiciones de la contratación pública estatal y no los términos de la contratación privada internacional. No se trata de un privado adquiriendo suministros para su empresa, sino de un Estado garantizando la salvaguarda de los derechos a la salud y la de sus habitantes. Las empresas farmacéuticas no son pares negociales sino prestadores de servicios, aun siendo multinacionales. Pero, se insiste, si bien estas aclaraciones se chocan siempre con la falta de información de los términos negociales, esta misma ausencia permite elaborar la hipótesis mencionada.

Puede que se busque asegurar el derecho a la salud e incluso la vida, pero no se pueden eliminar de tajo los múltiples mecanismos que buscan garantizar la transparencia en los procesos de contratación pública, así estemos en una situación calamitosa. Lo que desde la perspectiva del derecho civil negocial-contractual, el cual permite todo lo que no está expresamente prohibido, parece un punto de partida que debe darse por supuesto, resulta siendo, desde la perspectiva del derecho público, un inquietante problema de falta de control y de riesgos de ocultamientos cuestionable, pues los mecanismos de control en lo público son muy rigurosos. Es aquí donde la transparencia deviene problema jurídico de reflexión, pues el contexto no deja claro, y por tanto hace cuestionable, que el régimen de una negociación tan importante desde lo económico, lo social y lo político, sea el privado.

Por tanto, se trata aquí de una oportunidad de negocio que no tiene por qué reñir con una función pública de importancia histórica, es algo que ya se ha resaltado ${ }^{38}$, pues las farmacéuticas están teniendo un período de prosperidad debido a la pandemia. Según esto, el problema de tener o no en cuenta el principio de transparencia advierte que hay una normalización del asunto del secreto empresarial que es inquietante porque antepone el interés del lucro y oculta información bajo el pretexto de la confidencialidad. En un contexto en el que está en juego la salvaguarda de un derecho fundamental y la inversión un rubro muy alto de capital público, la vulneración del principio de transparencia es un problema social, ético, político, y, lo que es más importante para esta reflexión, jurídico.

El aspecto más importante de la sentencia C-145 de 2020 se encuentra en el salvamento de parcial de voto de los magistrados José Fernando Reyes Cuartas y Alberto Rojas Ríos. Va en línea con la inquietud planteada al comienzo en la pregunta respecto a la necesidad de la declaratoria de emergencia: "La Corte ha perdido una valiosa oportunidad para evitar que el Gobierno de la crisis se transforme en la regla general, cuando debe ser la excepción más reducida del Estado constitucional de derecho". Esa fue la disposición que llevó a que el Gobierno realizara una negociación tan importante para resolver la crisis de la covid-19 sin admitir ninguno de los controles que se consideran más que necesarios en un caso extraordinario como ese, en particular el de publicidad y transparencia para que fuera posible ejercer la vigilancia.

Es decir, que las situaciones extraordinarias deben ser admitidas extraordinariamente y estar sometidas a vigilancia, por tanto, también extraordinaria. Pero la consecuencia fue una ausencia total de claridad respecto a los pormenores del proceso. Un par de meses después de las notas periodísticas, los términos de la negociación seguían sin hacerse públicos y las vacunas empezaron a llegar en cantidades muy reducidas, lo que implicó un reproche adicional bajo la expresión ineficiencia.

Finalmente, los magistrados expresan lo siguiente en su salvamento parcial de voto:

“También debía realizarse un llamado a prevención al Gobierno nacional por un enfoque solidario, de derechos humanos y de cooperación internacional. Era necesario enfatizar en la protección central a la salud, vida y seguridad de las personas, tomar medidas especiales a favor de poblaciones vulnerables, desarrollar unas políticas con enfoque diferencial, mantener la interdependencia de los derechos humanos, tener en cuenta los principios de igualdad y no discriminación, observar la transparencia y

\footnotetext{
38 BOUDJELAL, M., NEHDI, A., ISLAM, I. Why do SARS-COV vaccines not exist? The pharma scientific intelligence and busi-
} ness model must be revisited! Expert Opinion on Drug Discovery, p. 1-3, 2020. DOI: 10.1080/17460441.2020.1777980. 
la información, además de la importancia de los demás derechos comprometidos, a saber, el trabajo, la educación, la subsistencia, entre otros".

Este es un aspecto de suma importancia que, por lo que se mencionó antes, resulta puesto en una situación subsidiaria respecto a la insistencia del Gobierno en los aspectos económicos de la emergencia. El enfoque debió estar puesto desde el comienzo en la salvaguarda de la salud como derecho fundamental y en la de los derechos que habilitan y hacen posible que la economía se pueda reactivar en los términos que le interesan al Gobierno. Pero el aspecto que los magistrados parecen mencionar de modo subsidiario, y que no resultó contemplado en el caso particular en torno al cual gira esta reflexión, la transparencia y la información.

Conviene ahora mencionar algunos aspectos relevantes de la condición impuesta por las regulaciones de la contratación pública, que son el aspecto que más interrogantes genera en las negociaciones que se llevaron a cabo entre el Gobierno y las farmacéuticas, las cuales, debido a la situación extraordinaria, no pueden ser vistas como meras empresas con fines de lucro. En el contexto de la pandemia, poseen una no declarada postura de proveedores de servicios públicos. Así que la necesidad de realizar la vigilancia de las actuaciones de ambas partes en la negociación, al menos a la luz de las exigencias impuestas por la salvaguarda del dinero público y, más importante aún, de un derecho fundamental, implicaba la necesaria aplicación de los controles establecidos por la normativa, en particular el de la aplicación el principio de transparencia.

\section{6 ¿Lucro o salud?: tensión entre libre mercado y derechos fundamentales}

Si bien, el debate que se plantea es de carácter jurídico, es necesario establecer un vínculo conceptual con el problema económico de la prevalencia del mercado en un contexto político en el que el sistema es democrático y en el que la salvaguarda de los derechos fundamentales es un deber estatal consagrado por la Constitución. Es decir, que se trata de una cuestión exclusivamente jurídica la cual, no obstante, establece enlaces inevitables con lo socioeconómico y con lo político. El primer aspecto establece el problema del lucro, pues, al tratarse del libre mercado en el contexto internacional y que se regula por la ley de la oferta y la demanda, es una aspiración que parece válida: los individuos aspiran a la máxima ganancia con la menor inversión. El segundo aspecto es el del compromiso del Estado colombiano con la protección de los derechos fundamentales en general y, en el caso de la adquisición de las vacunas para superar una pandemia, del derecho a la salud de modo masivo, pues se trata de un riesgo inminente para toda la población que, en primera instancia, justificó la declaratoria de la emergencia que se analizó en el apartado 1.

El debate se encuentra precisamente en este punto, pues no parece haber posibilidad de conciliar la aspiración de las farmacéuticas, que parece legítima, de obtener el máximo provecho de las negociaciones de la venta de la vacuna, con la obligación constitucional del Estado de elegir al proveedor idóneo de un servicio del que depende el restablecimiento de la normalidad tanto social como económica de Colombia. Se trata de una situación geopolítica inédita, pero la llegada de los lotes de vacunas es indicación de que el negocio que realizó el Gobierno colombiano con las farmacéuticas se dio en los términos del derecho privado.

El principio de transparencia para el caso de las negociaciones simplemente no operó porque no fue posible aplicar ningún instrumento de vigilancia. Es importante insistir en este punto que esta reflexión se plantea precisamente en ese déficit y se enfoca en interpretar su sentido. Por eso resulta determinante señalar esta disyuntiva que, a la luz de lo acontecido entre los meses de septiembre de 2020 y abril de 2021, resulta irresoluble. En efecto, prevaleció el interés por el lucro privado fomentado por las dinámicas de un mercado sin regulaciones sobre la necesidad pública de salvaguardar las finanzas estatales en un proceso de provisión del que depende un derecho fundamental. Que los documentos del proceso no se hayan hecho públicos produce la inquietud que motiva todo el planteamiento realizado hasta aquí. 
Desde la perspectiva de la necesidad de aplicar el principio de transparencia como fundamento del control, entendido y desplegado como la vigilancia lúcida que protege los intereses estatales, tanto en términos financieros como de salvaguarda del derecho a la salud, se plantean estas objeciones que permiten interpretar la negativa gubernamental a hacer públicos los términos de la negociación como un problema de legitimidad, credibilidad y confianza. La ausencia de la información, no solo en el contexto en el que los lotes de vacunas empezaron a llegar, sino en el del período en el que se estaban llevando a cabo las negociaciones, es una violación al principio de transparencia. No son necesarias especulaciones al respecto: la vigilancia, el criterio oportuno desde lo jurídico para evitar posibles afectaciones al interés público, no se pudo ejercer en el momento en el que era necesaria porque el Gobierno negoció con las farmacéuticas sin revelar ninguno de los aspectos involucrados. Se puede asegurar que se comportó como un particular en igualdad de condiciones con otro particular en una deliberación realizada en los términos del derecho privado. Y esto, desde la perspectiva política, ilegitima a un Estado al otorgarle la posición dominante a una multinacional. Y desde la perspectiva jurídica hace inoperante el derecho público cuando debería ser la base de la negociación. Los aspectos social, económico y político deben mencionarse aquí porque, en virtud de la posición negocial dominante de una multinacional, el Estado termina evidenciando una fragilidad que trasciende el aspecto jurídico, y se configura de este modo una crisis en su legitimidad, credibilidad y confianza.

Se trata, en suma, de una serie de objeciones a las negociaciones de adquisición de la vacuna a la luz del principio de transparencia al hacerlo inoperante por falta de aplicación de instrumentos de vigilancia. En general, las notas publicadas en los medios comunicación entre enero y febrero de 2021 parecieron asumir que era aceptable, como una especie de mal necesario debido a esta predominancia del lucro privado propio de la dinámica de mercado sin regulación, que el Gobierno no revelase los detalles de la negociación, en parte porque además asumen que lo que importa es contar con la vacuna en el menor tiempo posible. Pero el contexto internacional advierte que esto no es completamente cierto, pues Colombia no fue uno de los primeros países en iniciar el proceso de vacunación, así que el argumento de darle predominancia al principio de celeridad resulta siendo un argumento muy frágil. La explicación dada por el Gobierno, según la cual el proceso de contratación con las farmacéuticas es complejo y requiere de muchos detalles de orden técnico, solo complica la comprensión tanto de la dilatación en la entrega del suministro como de la confidencialidad que no permitió aplicar instrumentos de vigilancia y por los que los documentos, de evidente interés público, se mantuvieron reservados.

Pero los países que iniciaron con la vacunación con anterioridad y que tienen ritmos de vacunación razonables expresan de facto que algo no fue claro en el proceso llevado a cabo por el Gobierno colombiano: ¿por qué otros países lograron acuerdos con las farmacéuticas en plazos que han permitido que el proceso de vacunación empezara cuando el Gobierno colombiano seguía en negociaciones? Y, lo que es fundamental para este planteamiento, ¿por qué no se conocieron oportunamente los términos de la negociación, particularmente los que no comprometen el secreto empresarial e industrial y garantizan que haya transparencia? En efecto, en ninguna negociación se obliga a las farmacéuticas a revelar la fórmula de la vacuna, por lo cual resalta la importancia negocial de tener claro qué es lo que se puede revelar y qué es lo que se debe declarar confidencial. Aunque hay un movimiento inicialmente liderado por India y Sudáfrica que cada vez tiene más fuerza y reclama la liberación de las patentes. Para el momento en que se escribe este artículo dicha iniciativa ha tenido el respaldo de los EEUU a través de su Presidente y de la Comisión Europea que se declara dispuesta para debatir esta idea.

La vigilancia estatal puede de ejercerse sin que los intereses de las farmacéuticas, en tanto prestadoras de un servicio público al ser contratistas del Estado, se vean en riesgo. En efecto, como modo de conciliar estas dos exigencias aparentemente inconmensurables, ambas partes debieron hacer de público conocimiento las condiciones del contrato en las que se contemplaba la inversión. No se trata de una petición caprichosa, sino de una exigencia de legitimación porque se trata de dinero público, de inversión pública: el interés en el lucro por parte de las farmacéuticas no puede reñir con su rol como prestadores de un servicio público en 
un contexto totalmente inédito y en el que el beneficio financiero está garantizado por la necesidad global de enfrentar una pandemia.

Invocar el secreto empresarial o de patentes se asemeja mejor a una disculpa para no hacer público el acuerdo contractual del proceso de compraventa, lo cual despierta sospechas respecto al proceder del Gobierno porque se desentiende expresamente del principio de transparencia. No hacer esta distinción jurídica tan importante implica desconocimiento de los límites normativos y falta de pericia en la determinación de las condiciones del contrato a la luz de la normativa vigente. El Estado colombiano no es parte de un contrato privado en el que las farmacéuticas estén en igualdad, pues esto pone en duda la credibilidad, la legitimidad y la confianza en sus actuaciones. Un Estado que se encuentra en esa condición expresa su fragilidad ante una empresa que debe ser prestadora de servicios y no su igual y/o dominante en un proceso de negociación.

Esto manifiesta la tensión entre, por una parte, el modelo económico, basado en el capitalismo neoliberal, que considera cualquier control público como una intromisión en la libertad de mercado y empresa y, por la otra, el necesario control del gasto de los dineros públicos, de los cuales dependen la legitimidad, la credibilidad y la confianza del Estado. Después de más de un año de pandemia, ningún pretexto sobre la disponibilidad de la vacuna justifica el secretismo. Las farmacéuticas no pueden pretextar que se trata de la oferta y la demanda del mercado porque de por medio está el derecho fundamental a la salud, además de que se trata de un compromiso netamente negocial de cumplir con el suministro exigido. A manera de ejemplo puede mencionarse el conflicto existente entre la farmacéutica AstraZeneca y la Unión Europea por la demora en la entrega de vacunas y la falta de transparencia en este proceso y la decisión de la última de demandar a la empresa anglo sueca y no renovar el contrato de suministro de vacunas más allá de junio de 2021.

Las farmacéuticas están, por tanto, en la condición paradójica y doblemente privilegiada de que no se responsabilizan de la salvaguarda de un derecho y, además, de que podrán satisfacer la demanda cuando sus medios de gestión lo permitan porque la complejidad del desarrollo de la vacuna les da ese privilegio ${ }^{39}$, lo cual es debatible porque los estudios para tales desarrollos nunca empiezan desde cero y aprovechan los antecedentes: la investigación sobre la COVID-19 cuentan con el apoyo de todo lo investigado sobre el conjunto de enfermedades SARS. Un Gobierno responsable no puede poner a un privado en una situación de doble beneficio en el que no hay mecanismo de control que verifique las instancias del proceso.

Según lo anterior, el Gobierno queda en una posición altamente comprometida en lo que respecta a su gestión de la pandemia, pues, según lo dicho en este contexto, parece mejor un mal negociante que, sin los debidos controles, invierte un rubro preocupantemente alto de los impuestos en un negocio de alta prioridad pública pero que no puede ni controlar ni vigilar. Esto, a diferencia de lo que parece razonable a la luz de la economía, no es el triunfo del libre mercado sino, la vulneración del Estado Constitucional de Derecho por omisión del principio de transparencia.

De modo pues, que el hecho de que la ley de oferta y demanda esté por encima de la salvaguarda de un derecho como la salud, y particularmente cuando hay una negociación que involucra dineros públicos y en la que no se ejercen los controles necesarios para ponderar el interés privado por el lucro con la protección efectiva de un derecho, implica que la desatención al principio de transparencia condujo, en un contexto tan complejo como el de la pandemia de la COVID-19, a que el interés negocial primara sobre la institucionalidad misma del Estado Social de Derecho. La pandemia puso a prueba nuestras instituciones y la necesidad de obtener las vacunas para enfrentarla quebrantó nuestro ordenamiento jurídico.

¿Qué significa, entonces, esta omisión que, debido precisamente a la ausencia de la vigilancia y de la transparencia y a la falta de publicidad de los documentos necesarios, se puede considerar deliberada? La libertad de negociación que permite el modelo económico, basado en el capitalismo neoliberal, deviene

39 CALNAN, M., DOUGLASS, T. Hopes, hesitancy and the risky business of vaccine development. Health, Risk and Society, v. 22, n. 5-6, p. 291-304, 2020. DOI: 10.1080/13698575.2020.1846687. 
excusa para que el Gobierno negocie con rubros altos de los impuestos, en un contexto de pandemia y de riesgo manifiesto para la salud que motivó una emergencia que se había extendido por más de un año, sin que medien los controles necesarios para determinar si la aspiración de lucro de los operadores privados fue más importante que el bien público que la inversión de los recursos públicos deben salvaguardar.

Como debate jurídico, la vigilancia sobre el gasto de los dineros públicos y la posición de las empresas farmacéuticas multinacionales como algo más que meros proveedores de servicios y de su nuevo rol como prestadores del servicio público de suministro de un producto prioritario para la atención en salud, en un contexto inédito y de altísimo riesgo para la salvaguarda del derecho a la salud de un país como Colombia, hace que sea necesario aplicar los controles establecidos por la ley de contratación estatal, por lo que el proceso de adquisición de las vacunas para la COVID-19 por parte del Gobierno colombiano plantean una crisis que supera lo jurídico y se convierte en un problema de legitimidad, confianza y credibilidad y aún es pronto para determinar las consecuencias de la ausencia de controles en el proceso de adquisición de las vacunas y los problemas jurídicos, políticos y económicos que este actuar omisivo podrían traer en un país que para el memento en que se escribe el presente texto se encuentra en la mayor crisis social de su historia.

\section{Conclusión}

Se pueden declarar cuatro elementos a partir de lo antedicho como un modo de orientar el debate jurídico sobre la ausencia de documentación legal que permitiera realizar la debida vigilancia atendiendo el principio de transparencia para el caso de la adquisición de las vacunas para la COVID-19 en el marco de la Emergencia decretada por el Gobierno Nacional con motivo de la pandemia.

Lo primero, y lo más importante como resultado de la exploración de la hipótesis de trabajo, es que la ausencia de transparencia en el proceso de negociación para adquirir las vacunas contra la COVID-19, en un contexto de pandemia, produce una crisis de legitimidad, credibilidad y confianza en el Estado colombiano. Basta con plantear, a partir de la ausencia de los documentos esperados para tal efecto, que no poder aplicar el principio de transparencia a través de un instrumento de vigilancia durante el proceso de negociación implica que la posición dominante del Estado en un contexto determinado por la predominancia de la normativa pública no existe, y que el Estado actuó como privado en posición de igualdad o incluso inferioridad con un privado que debería admitir su posición como simple prestador de servicios.

Lo segundo se desprende de lo antedicho. Que el proceso se haya llevado a cabo sin ningún instrumento de vigilancia, el cual, conviene insistir, se debió aplicar durante el proceso de negociación, y que haya tenido las consecuencias que tuvo indica que las multinacionales tuvieron la potestad de tratar a los estados como a un cliente que necesita una mercancía escasa en un contexto donde había muchos más clientes buscando lo mismo y dispuestos a pagar mayores precios. La manera como las farmacéuticas y muchos estados asumieron la negociación y adquisición de las vacunas es reprochable, pues actos de acaparamiento y acceso desigual a las mismas. Los estados ricos no dudaron en asegurarse grandes cantidades de vacunas sin importar el precio, mientras que los pobres quedaron a la espera de lo que las condiciones del mercado les pudieran ofrecer.

Lo tercero es que la posición dominante de las farmacéuticas, en el contexto del libre mercado carente de regulaciones estatales, hace que se olvide un aspecto determinante: todo privado que contrata con el Estado es prestador de un servicio y está sujeto a vigilancia. Este es posiblemente el elemento que despierta las mayores inquietudes. Zygmunt Bauman (2009) expresa esta inquietud en Modernidad líquida:

"Hay poco que los Estados soberanos de hoy puedan hacer, y menos aún que sus gobiernos se atrevan a llevar a cabo, para contener las presiones del capital, las finanzas y el comercio (incluido el comercio cultural) de carácter globalizado. Si se vieran instados por sus sujetos a reafirmar sus propias normas de justicia y propiedad, los gobiernos en su mayor parte replicarían que nada pueden hacer al respecto 
sin 'ahuyentar a los inversores' y por ende atentar contra el PBN y el bienestar de la nación y todos sus miembros" (Bauman, 2008, p. 92).

Y añade:

"Dirían que las reglas del juego que están obligados a jugar han sido dispuestas (y pueden ser revisadas a voluntad) por fuerzas sobre las que tienen una influencia mínima, si es que tienen alguna. ¿Cuáles fuerzas? Unas tan anónimas como los nombres tras los que se esconden: competencia, condiciones de comercio mercados mundiales, inversores globales. Fuerzas sin residencia fija; extraterritoriales, a diferencia de los poderes territoriales del Estado; y capaces de moverse libremente alrededor del planeta, en contraste con las agencias del Estado que, o bien para peor o bien para mejor, se mantienen irrevocablemente sujetas al suelo. Fuerzas cambiantes y huidizas, esquivas, difíciles de localizar e imposibles de atrapar" ${ }^{{ }^{40}}$.

Lo que el filósofo advierte es que una de las consecuencias de la globalización es que los estados se han vuelto porosos, el capital se mueve entre los estados sin ningún tipo de regulación ni control, y que son los estados los que se ven forzados a simular que es el capital el que sigue sus dictados. Cuando domina el postulado de que el estado se debe someter al mercado, poniendo este en donde sea posible y dejando aquél donde sea necesario, su fragilidad es de una claridad palmaria, y queda abierta la posibilidad de emplear esta condición como pretexto para desestimar la vigilancia. Que el principio de transparencia simplemente se haya obviado en el caso del Estado colombiano frente a las multinacionales farmacéuticas lo expresa. De eso se ha tratado en este artículo,

Y, como cuarto aspecto, se puede afirmar que hay una inconsistencia normativa en la invocación de la confidencialidad, pero debido a que lo asumido fue el criterio de la negociación privada, con lo cual la invocación de la necesidad de aplicar instrumentos de vigilancia como manifestación del principio de transparencia fue eludida. Este elemento queda abierto precisamente porque parece no implicar discusiones o confusiones. El Gobierno colombiano, en el contexto de la emergencia sanitaria que dura ya más de un año, negoció un producto de necesidad manifiesta para todo el país, usando dineros públicos, pero sin aplicar la normativa esperada en tal caso.

Así, pues, la transparencia como principio de la contratación pública terminó desatendida en el caso de la negociación para la compra de las vacunas del COVID-19 por dos factores fundamentales: primero, la imposibilidad de contar con los documentos oficiales, lo cual llevó a que fuera necesario emplear fuentes periodísticas; y segundo, la ausencia de precisión respecto al modo como se llevaron a cabo de las negociaciones, las cuales, al estar caracterizadas por la confidencialidad -la cual se denomina secretismo cuando tiene un sustento normativo débil- hace que los mecanismo de vigilancia resulten inoperantes.

Además, desde el Decreto que declaró por primera vez la emergencia por motivo de la pandemia, es claro que ni el derecho fundamental a la vida ni el derecho fundamental a la salud fueron prioridad para los intereses del Gobierno Nacional. El énfasis estuvo puesto siempre en la salvaguarda de la economía, lo cual resulta paradójico cuando se lo contrasta con el posible descuido en el marco de las negociaciones con las farmacéuticas. Esto advierte que no hubo una adecuada aplicación del principio de planeación, en particular porque los aspectos sociales de la pandemia, anejos a los derechos mencionados, no recibieron la atención que necesitaban del mismo modo que el aspecto económico.

En línea con lo anterior, el acceso a la información resulta precario, tendiente a la especulación sin evidencias, dependiente de unas cuantas notas periodísticas que parecen asumir que el proceso no puede desarrollarse sino de ese modo secretista. En realidad, este contexto no es otro que el de la más completa desinformación. No se pueden hacer suposiciones respecto a los posibles reproches desde lo normativo, pero la sola ausencia de publicidad, y la respectiva vigilancia que permita salvaguardar el principio de transparencia, permiten plantear la hipótesis del cuestionamiento de la actuación misma del Gobierno en un

${ }_{40}$ BAUMAN, Zygmunt. Modernidad Líquida. Buenos Aires: FCE, 2008. 
tema que deviene sensible debido a una doble condición pública: el dinero invertido y la salvaguarda de un derecho fundamental imprescindible para cualquier dinámica social.

Idealmente, la transparencia no debería estar asociada tan directamente con la corrupción como la asocian las leyes mencionadas, y tampoco debería estar asociada con el control. La vigilancia, en cuanto prevención, resulta siendo un aspecto más sano en términos de derecho que la necesidad de sanción, en particular cuando se ejerce un control cuando las actuaciones cuestionables han devenido delictivas, con las consecuencias que esto le genera a la administración de justicia.

Finalmente, el principio de transparencia como fundamento de la vigilancia y la prevención que puede propiciar está anclada en la legitimidad, entendida como la aplicación de la normativa que evita los conflictos con el sentido de la justicia, en la credibilidad, entendida como la determinación armónica y consistente de los datos proporcionados según las exigencias de claridad del proceso antes que del control y en la confianza , entendida como la situación de consonancia entre las actuaciones estatales y las aspiraciones de cada ciudadano respecto a ella. Se trata de elementos determinantes para la transformación del imaginario social desfavorable respecto al Estado y que, en el caso de la negociación de la vacuna para el COVID-19 por parte del Gobierno, volvieron a quedar pendientes.

Así pues, hay una relación conflictiva entre la propuesta teórica o abstracta del principio de transparencia y la contribución práctica que podría hacer si se la separa de este vínculo tan estrecho con la corrupción. Esto se debe a la dispersión normativa, a la confusión conceptual y al uso negativo, reducido y punitivo del principio, lo que lleva a que su operatividad sea excesivamente limitada, restringida a aspectos no positivos o constructivos que el mismo principio puede ofrecer, como la no aprovechada posibilidad de hacerle vigilancia al proceso de negociación de la compra de las vacunas de la COVID-19.

Al menos, se puede afirmar que se trata de una posibilidad que está abierta pero que no se ha aprovechado debidamente en el contexto de los procesos del ámbito de juridicidad público debido a un énfasis excesivo en emplearlo como mecanismo sine qua non tipificado mayoritariamente bajo la forma de advertencia. Existen alternativas no aprovechadas para que el principio no sea simplemente necesario, sino que se pueda proponer como base de una razón suficiente en lo que respecta a un cambio en la mentalidad o imaginario del entorno sociopolítico, proclive a la sospecha y a la disposición punitiva antes que a la confianza y a la disposición a la apertura sin prevenciones.

Es de anotar que en una decisión de tutela del 21 de mayo de 2021 el Tribunal Superior de Cundinamarca le ordenó a la Unidad Nacional de Gestión de Riesgo de Desastres (UNGRD) que le entregue al tutelante una copia de los contratos de adquisición de las vacunas. Expresa el Tribunal que las cláusulas de confidencialidad impuestas por las farmacéuticas son inaplicables en un Estado Constitucional de Derecho. La anterior decisión reafirma la hipótesis del presente artículo, pues un particular así sean las farmacéuticas en tiempo de pandemia no pueden imponerle al Estado un secretismo contractual y que renuncie a los mecanismos de control que permiten que una negacioncita con dineros públicos sea transparente, pues de hacerlo quien está en riesgo es el mismo Estado Constitucional de Derecho.

\section{Referencias}

ALEJANDRA VITALE, María. Discurso presidencial sobre el COVID-19. El caso de Alberto Fernández en Argentina. deSignis, v. 33, p. 113-125, Jul. 2020. DOI: https://doi.org/10.35659/designis.i33p113-125.

ARELLANO GAULT, David. Transparencia desde un análisis organizativo: los límites del nuevo institucionalismo económico y las "fallas de transparencia". Revista del CLAD Reforma y Democracia, n. 40, p. 53-80, feb. 2008. 
BAUMAN, Zygmunt. Modernidad Líquida. Buenos Aires: FCE, 2008.

BELLO PAREDES, Santiago A. Covid-19 y estado de derecho: España. Utopia y Praxis Latinoamericana, v. 25, n. Esp.4, 2020. DOI: https://doi.org/10.5281/zenodo.3931042

BILLINGTON, J.; DESCHAMPS, I.; ERCK, S. C.; GERBERDING, J.L.; HANON, E.; IVOL, S.; SHIVER, J.W.; SPENCER, J.A.; VAN HOOF, J. Developing Vaccines for SARS-CoV-2 and Future Epidemics and Pandemics: Applying Lessons from Past Outbreaks. Health Security, v. 18, n. 3, p. 241-249, 2020. DOI: 10.1089/hs.2020.0043.

BOSSANO LOMELLINI, Luis Miguel. La subasta inversa: un mecanismo de contratación pública eficiente y transparente. Derecho PUCP, n. 66, p. 277-285, dic./jun. 2011.

BOUDJELAL, M.; NEHDI, A.; ISLAM, I. Why do SARS-COV vaccines not exist? The pharma scientific intelligence and business model must be revisited! Expert Opinion on Drug Discovery, p. 1-3, 2020. DOI: 10.1080/17460441.2020.1777980.

BRULL-GONZÁLEZ, Maribel. Sistema de información y comunicación para el enfrentamiento de las comunidades a desastres naturales, epidemias y pandemias. Ciencia en su PC, v. 1, n. 3, p. 1-17, Jul./Sep. 2020.

CALNAN, M., DOUGLASS, T. Hopes, hesitancy and the risky business of vaccine development. Health, Risk and Society, v. 22, n. 5-6, p. 291-304, 2020. DOI: 10.1080/13698575.2020.1846687

CASTRO DE CIFUENTES, Marcela. Los contratos normativos y los contratos marco en el derecho privado contemporáneo. Revista Estudios Socio-Jurídicos, v. 21, n. 1, p. 121-150, Ene./Jun. 2019. DOI: https://doi. org/10.12804/revistas.urosario.edu.co/sociojuridicos/a.6977

CHACÍN FUENMAYOR, Ronald; VILLA-VILLA, Sandra; BERROCAL-DURAN, Juan Carlos. Interpretación democrática de la constitución colombiana en tiempos de crisis (pandemia COVID-19). Utopia y Praxis Latinoamericana, v. 25, n. Esp.8, 2020. DOI: https://doi.org/10.5281/zenodo.4082009

DA CONCEIÇÃO LIMA, Luciana Cristina, et al. Compliance em tempos de calamidade pública: análise sobre a flexibilização da transparência de dados e informações durante o enfrentamento da COVID-19 no Brasil. Revista Brasileira de Políticas Públicas, v. 11, n. 1, 2021.

DA SILVA, Alice Rocha; SANTOS, Ruth MP. A influência do direito administrativo global no processo brasileiro de contratação pública à luz do princípio da transparência. Revista Brasileira de Políticas Públicas, v. 6, n. 2, p. 66-88, 2016.

DADICO, Claudia María. Epidemias, pandemias e o ódio: caminhos para a governamentalidade da pandemia da Covid-19. Publicum, v. 6, n. 1, 2020

DO AMARAL, Marcelo Quevedo. A transparência da política monetária e a sua limitação aos objetivos constitucionais. Revista Brasileira de Políticas Públicas, v. 8, n. 1, p. 706-724, 2018.

DUQUE BOTERO, Juan David. Los principios de transparencia y publicidad como herramientas de lucha contra la corrupción en la contratación del Estado. Revista Digital de Derecho Administrativo, n. 24, p. 79-101, 2020. DOI: $10.18601 / 21452946 . n 24.04$

DUQUE: revelar contratos de vacunas contra la covid 'tumbaría' la compra. Revista Semana, Bogotá. 15/01/2021. Disponible en https://bit.ly/3obmv61

EMMERICH, Gustavo Ernesto. Transparencia, rendición de cuentas, responsabilidad gubernamental y participación ciudadana. Polis: Investigación y Análisis Sociopolítico y Psicosocial, v. 2, n. 4, p. 67-90, segundo semestre, 2004.

FERNÁNDEZ MALLOL, Antonio Luis. La integridad del procedimiento de contratación pública en el derecho de la Unión. Europea. El conflicto de interés y su incidencia sobre la regulación de las prohibicio- 
nes. Para contratar, las causas de incompatibilidad y las disposiciones sobre transparencia y buen gobierno. Revista de Estudios de la Administración Localy Autonómica, n. 2, p. 117-130, jul./dic. 2014.

GARCÍA OTERO, Ruth; HERNÁNDEZ PALMA, Oona Isabel. Derechos humanos y mecanismos de control normativo internacional en el marco de la pandemia. Covid-19: reflexión desde el control de convencionalidad. Utopia y Praxis Latinoamericana, v. 25, n. Esp.8, 2020. DOI: https://doi.org/10.5281/zenodo.4082011

GATTI, Franco. La corrupción en la emergencia: repercusiones sobre los derechos humanos. Revista IIDH, n. 72, p. 89-112, 2020.

GILLI, Juan José. La transparencia como objetivo del desarrollo sostenible. Ciencias Administrativas, n. 9, 2017.

GONZÁLEZ RÍOS, Isabel. La transparencia como principio vertebrador de la contratación pública: significado y problemas de articulación normativa. Revista de Estudios de la Administración Localy Autonómica, n. 12, p. 6-25, oct./mar. 2019. DOI: 10.24965/reala.i12.10714.

GOTTARDELLO, D. The relationship between intellectual property and human right and a policy oriented recommendations. NTUT Journal of Intellectual Property Law and Management, v. 7, n. 2, p. 90-105, 2019.

HINESTROSA, FERNANDO. Teoría de la imprevisión. Revista de Derecho Privado, n. 39, p. 9-29, Jul./Dic. 2020. DOI: $10.18601 / 01234366 . n 39.02$

KONDRAT'EVA, N.B., KHROMAKOV, D.O. EU pharmaceutical market: Problems of competition. World Economy and International Relations, v. 64, n. 2, p. 53-62, 2020. DOI: 10.20542/0131-2227-2020-64-2-53-62

LARA ARIAS, Carlos Alberto. Mecanismos de control en la contratación estatal como elemento de la lucha anticorrupción. En-Contexto Revista de Investigación en Administración, Contabilidad, Economía y Sociedad, n. 1, p. 37-65, ene./dic. 2013.

LASZCZYK, A. Anticompetitive patent settlements - where are we ten years after the European Commission's pharmaceutical inquiry? Yearbook of Antitrust and Regulatory Studies, v. 13, n. 21, p. 129159, 2020. DOI: 10.7172/1689-9024.YARS.2020.13.21.5

LAURELL, Asa Cristina. Las dimensiones de la pandemia de Covid-19. El trimestre econ, Ciudad de México, v. 87, n. 348, p. 963-984, dic. 2020. Disponible en http://www.scielo.org.mx/scielo.php?script=sci_ arttext\&pid=S2448-718X2020000400963\&lng=es\&nrm=iso. accedido en: 27 dic. 2021. Epub 05-Mar2021. https://doi.org/10.20430/ete.v87i348.1153

LIMA, Luciana Cristina da Conceição; GONÇALVES, Alcindo Fernandes; REI, Fernando Cardoso Fernandes; LIMA, Cláudio Benevenuto de Campos. Compliance em tempos de calamidade pública: análise sobre a flexibilização da transparência de dados e informações durante o enfrentamento da COVID-19 no Brasil. Revista Brasileira de Políticas Públicas, Brasília, v. 11, n. 1. p. 168-187, 2021.

MALARET, Elisenda. El nuevo reto de la contratación pública para afianzar la integridad y el control: reforzar el profesionalismo y la transparencia. Revista Digital de Derecho Administrativo, n. 15, p. 21-60, 2016. DOI: 10.18601/21452946.n15.04

OLMO, G. Vacunas contra el coronavirus: a qué se debe el secretismo que rodea los contratos entre los gobiernos y las farmacéuticas. 28/01/2021. Disponible en: https://www.bbc.com/mundo/noticias-internacional-55804567

OSORES PLENGE, Fernando; GÓMEZ BENAVIDES, Jorge; SUAREZ OGNIO, Luis; CABEZAS SÁNCHEZ, César; ALAVE ROSAS, Jorge; MAGUIÑA VARGAS, Ciro. Un nuevo virus A/H1N1, una nueva pandemia: Influenza un riesgo permanente para una humanidad globalizada. Acta Médica Peruana, v. 26, n. 2, p. 97-130, 2009. 
PECETTA, S., FINCO, O., SEUBERT, A. Quantum leap of monoclonal antibody (mAb) discovery and development in the COVID-19 era. Seminars in Immunology, 50, art. no. 101427, 2020. DOI: 10.1016/j. smim.2020.101427

PIZARRO WILSON, Carlos. Un vistazo general a los Principios Latinoamericanos de Derecho de los Contratos. Revista de Derecho Privado, n. 35, p. 351-368, Jul./Dic. 2018. DOI: 10.18601/01234366.n35.13

POZO, N. F. Confidencialidad, privacidad y transparencia en el arbitraje internacional. Revista de Derecho Privado, v. 40, p. 465-494, dic. 2020. DOI: https://doi.org/10.18601/01234366.n40.16.

PRADERE PENSADO, Juan Carlos; CHAO GONZÁLEZ, Susana; GARCÍA GÓMEZ, Alberto; GUTIÉRREZ GUTIÉRREZ, Luisa. Consideraciones éticas sobre la atención médica en situaciones de desastre. MEDISAN, v. 16, n. 8, p. 1295-1305, 2012.

REDACCIÓN JUSTICIA. ¿Puede el Gobierno tener en secreto contratos de vacunas contra covid? Periódico El Tiempo, 2021. Disponible en https://bit.ly/3b8Vxq8

REPÚBLICA DE COLOMBIA. Corte Constitucional. Sentencia C-004 de 2017.

REPÚBLICA DE COLOMBIA. Corte Constitucional. Sentencia C-1016 de 2012.

REPÚBLICA DE COLOMBIA. Corte Constitucional. Sentencia C-145 de 2020

REPÚBLICA DE COLOMBIA. Corte Constitucional. Sentencia C-193 del 2011.

REPÚBLICA DE COLOMBIA. Corte Constitucional. Sentencia C-307 de 2020.

REPÚBLICA DE COLOMBIA. Corte Constitucional. Sentencia C-620 de 2010.

REPÚBLICA DE COLOMBIA. Ministerio de Salud. Boletín de Prensa No 089 de 2021. 25/01/2021. Disponible en: https://www.minsalud.gov.co/Paginas/Colombia-continua-en-conversaciones-para-compra-de-mas-vacunas.aspx

REPÚBLICA DE COLOMBIA. Presidencia de la República. Decreto 417 del 17 de marzo de 2020

REPÚBLICA DE COLOMBIA. Presidencia de la República. Decreto 637 del 6 de mayo de 2020

REVILLA VERGARA, Ana Teresa. La transparencia en la ley de contrataciones del Estado. Derecho PUCP, n. 66, p. 195-221, dic./jun. 2011.

SANDOVAL BALLESTEROS, Irma Eréndira. Hacia un proyecto "democrático-expansivo" de transparencia. Revista Mexicana de Ciencias Politicas y Sociales, v. LVIII, n. 219, p. 103-134, sep./dic. 2013.

SANDOVAL-ALMAZÁN, Rodrigo. Gobierno abierto y transparencia: construyendo un marco conceptual. Convergencia. Revista de Ciencias Sociales, v. 22, n. 68, p. 203-227, mayo/ago. 2015.

SANTORO, M., SHANKLIN, R. Human rights obligations of drug companies. Journal of Human Rights, v. 19, n. 5, p. 557-567, 2020. DOI: 10.1080/14754835.2020.1820315

SCHELLER D’ANGELO, André; SILVA MAESTRE, Shirly. La corrupción en la contratación pública: operatividad, tipificación, percepción, costos y beneficios. Revista VIA IURIS, n. 23, p. 1-36, jul.dic. 2017.

SEHGAL, R.K. \& KOUL, R.L. Whither to Public Interest? The Curious Case of Compulsory Drug Licensing in Indian Pharmaceutical Industry. Indian Journal of Forensic Medicine and Toxicology, v. 14, n. 4, p. 93029306, 2020. DOI: $10.37506 /$ ijfmt.v14i4.13202

SMITH, Adam. La riqueza de las naciones, libro IV, cap. II, p. 456-457.

STAKHEYEVA, H. Intellectual property and competition law: Understanding the interplay. Multi-Dimensional Approaches Towards New Technology: Insights on Innovation, Patents and Competition, p. 3-19, 2018. DOI: 10.1007/978-981-13-1232-8_1 
SYED, S. Incorporation of competition-related TRIPS flexibilities in the domestic law: A case study of India. Journal of World Intellectual Property, v. 23, n.1-2, p. 2-20, 2020. DOI: 10.1111/jwip.12137

TORREELE, E. Business-as-Usual will not Deliver the COVID-19 Vaccines We Need. Development Basingstoke), v. 63, n. 2-4, p. 191-199, 2020. DOI: 10.1057/s41301-020-00261-1

URBINA-MEDINA, Huníades; NOGUERA BRIZUELA, Dalmacia; LEVY MIZHARY, José; CARRIZO, Juan III; BETANCOURT, Adelfa. Comunicación efectiva y ética en casos de epidemias y pandemias. Archivos Venezolanos de Puericultura y Pediatría, v. 79, n. 4, p. 113-117, oct./dic. 2016

UVALLE BERRONES, Ricardo. Fundamentos de la transparencia en la sociedad contemporánea. Revista Mexicana de Ciencias Políticas y Sociales, v. LXI, n. 226, p. 199-220, ene./abr. 2016.

VALENCIA-GRAJALES, José Fernando; MARÍN-GALEANO, Mayda Soraya. SARS-CoV-2 y la debacle del Estado, la justicia, la democracia, el capitalismo y el inicio de la era de la vigilancia. Ratio Juris, v. 15, n. 30, 2020. DOI: $10.24142 /$ raju.v15n30a1

VEGA DE HERRERA, Mariela. Aplicación de los principios de igualdad y transparencia en la contratación pública de España y de Colombia. Prolegómenos. Derechos y Valores, v. VIII, n. 16, p. 67-78, jul./dic. 2005.

WACHSMANN, A., ZACHARIE, N. Generics: The French Competition Authority fines a pharmaceutical company for an abuse of its dominant position having delayed and then limited generic entry (Fentanyl transdermal patches). Concurrences, v. 2, 2018.

ZAMBRANO, Virginia et al. O DIREITO À SAÚDE E À VIDA EM CONFRONTO COM O DIREITO À PROPRIEDADE INTELECTUAL DOS LABORATÓRIOS, NO ÂMBITO DA PANDEMIA DA COVID 19: A POSSIVEL QUEBRA DE PATENTES. Revista Juridica, [S.1.], v. 5, n. 62, p. 168 - 192, jan. 2021. ISSN 2316-753X. Disponível em: http://revista.unicuritiba.edu.br/index.php/RevJur/article/ view/4906/371373083. Acesso em: 24 dez. 2021. doi:http://dx.doi.org/10.21902/revistajur.2316-753X. v5i62.4906. 
Para publicar na revista Brasileira de Políticas Públicas, acesse o endereço eletrônico www.rbpp.uniceub.br

Observe as normas de publicação, para facilitar e agilizar o trabalho de edição. 